\title{
Canadian Consensus Conference on the management of gastroesophageal reflux disease in adults - Update 2004
}

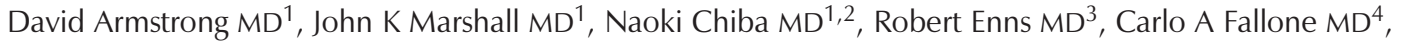 \\ Ronnie Fass $M D^{5}$, Roger Hollingworth $M D^{6}$, Richard $\mathrm{H}_{\text {Hunt }} \mathrm{MD}^{1}$, Peter J Kahrilas $M D^{7}$, Serge Mayrand $M D^{4}$, \\ Paul Moayyedi MD ${ }^{1,8}$, William G Paterson $M D^{9}$, Dan Sadowski MD $^{10}$, Sander JO Veldhuyzen van Zanten MD $^{11}$, \\ for the Canadian Association of Gastroenterology GERD Consensus Group*
}

\begin{abstract}
D Armstrong, JK Marshall, N Chiba, et al; for the Canadian Association of Gastroenterology GERD Consensus Group. Canadian Consensus Conference on the management of gastroesophageal reflux disease in adults - Update 2004. Can J Gastroenterol 2005;19(1):15-35.
\end{abstract}

BACKGROUND: Gastroesophageal reflux disease (GERD) is the most prevalent acid-related disorder in Canada and is associated with significant impairment of health-related quality of life. Since the last Canadian Consensus Conference in 1996, GERD management has evolved substantially.

OBJECTIVE: To develop up-to-date evidence-based recommendations relevant to the needs of Canadian health care providers for the management of the esophageal manifestations of GERD.

CONSENSUS PROCESS: A multidisciplinary group of 23 voting participants developed recommendation statements using a Delphi approach; after presentation of relevant data at the meeting, the quality of the evidence, strength of recommendation and level of consensus were graded by participants according to accepted principles. OUTCOMES: GERD applies to individuals who reflux gastric contents into the esophagus causing symptoms sufficient to reduce quality of life, injury or both; endoscopy-negative reflux disease applies to individuals who have GERD and a normal endoscopy. Uninvestigated heartburn-dominant dyspepsia - characterised by heartburn or acid regurgitation - includes erosive esophagitis or endoscopy-negative reflux disease, and may be treated empirically as GERD without further investigation provided there are no alarm features. Lifestyle modifications are ineffective for frequent or severe GERD symptoms; over-the-counter antacids or histamine $\mathrm{H}_{2}$-receptor antagonists are effective for some patients with mild or infrequent GERD symptoms. Proton pump inhibitors are more effective for healing and symptom relief than histamine $\mathrm{H}_{2}$-receptor antagonists; their efficacy is proportional to their ability to reduce intragastric acidity. Response to initial therapy - a once-daily proton pump inhibitor unless symptoms are mild and infrequent (fewer than three times per week) - should be assessed at four to eight weeks. Maintenance medical therapy should be at the lowest dose and frequency necessary to maintain symptom relief; antireflux surgery is an alternative for a small proportion of selected patients. Routine testing for Helicobacter pylori infection is unnecessary before starting GERD therapy. GERD is associated with Barrett's epithelium and esophageal adenocarcinoma but the risk of malignancy is very low. Endoscopic screening for Barrett's epithelium may be considered in adults with GERD symptoms for more than 10 years; Barrett's epithelium and low-grade dysplasia generally warrant surveillance; endoscopic or surgical management should be considered for confirmed high-grade dysplasia or malignancy.

CONCLUSION: Prospective studies are needed to investigate clinically relevant risk factors for the development of GERD and its complications; GERD progression, on and off therapy; optimal management strategies for typical GERD symptoms in primary care patients; and optimal management strategies for atypical GERD symptoms, Barrett's epithelium and esophageal adenocarcinoma.

Key Words: Barrett's epithelium; Endoscopy negative reflux disease; Erosive esophagitis; Gastroesophageal reflux disease (GERD); Proton pump inhibitor (PPI)

\section{La conférence consensuelle canadienne sur la prise en charge du reflux gastroœsophagien pathologique : Mise à jour 2004}

HISTORIQUE : Le reflux gastroœsophagien pathologique (RGOP) est le trouble acidobasique le plus prévalent au Canada, et il s'associe a une défaillance marquée de la qualité de vie reliée à la santé. Depuis la dernière conférence consensuelle canadienne de 1996, la prise en charge du RGOP a énormément progressé.

OBJECTIF : Élaborer des recommandations à jour fondées sur des faits probants applicables aux besoins des dispensateurs de soins canadiens pour la prise en charge des manifestations œesophagiennes du RGOP. PROCESSUS CONSENSUEL : Un groupe multidisciplinaire de 23 participants ayant droit de vote ont élaboré des recommandations au moyen de la méthode Delphi. Après avoir présenté les données pertinentes en réunion, la qualité des données probantes, la solidité des recommandations et le taux de consensus ont été classés par les participants d'après des principes acceptés.

ISSUES : Le RGOP s'applique aux individus dont le contenu du reflux dans l'œsophage provoque assez de symptômes pour réduire la qualité de vie, causer des lésions ou les deux. Le reflux négatif à l'endoscopie

${ }^{1}$ Division of Gastroenterology, McMaster University, Hamilton; ${ }^{2}$ Surrey GI Research, Guelph, Ontario; ${ }^{3}$ University of British Columbia,

Vancouver, British Columbia; ${ }^{4} \mathrm{McGill}$ University Health Centre, Montreal, Quebec; ${ }^{5}$ University of Arizona, Phoenix, Arizona, USA;

${ }^{6}$ Credit Valley Hospital, Mississauga, Ontario; ${ }^{7}$ Northwestern University, Chicago, Illinois, USA; ${ }^{8}$ University of Birmingham, Birmingham,

United Kingdom; ' ${ }^{9}$ Queen's University, Hotel Dieu Hospital, Kingston, Ontario; ${ }^{10}$ Royal Alexandra Hospital, Edmonton, Alberta; ${ }^{11}$ Dalhousie

University, Queen Elizabeth II Health Sciences Centre, Halifax, Nova Scotia; *See list of voting participants in the appendix

Correspondence: Dr David Armstrong, Division of Gastroenterology, HSC-4W8, McMaster University Medical Centre, 1200 Main Street West,

Hamilton, Ontario L8N 325. Telephone 905-521-2100 ext 76404, fax 905-521-4958, e-mail armstro@mcmaster.ca

Received and accepted for publication October 20, 2004 
s'applique aux personnes qui souffrent de RGOP et dont l'endoscopie est normale. Une dyspepsie dominée par des brûlures d'estomac non explorées, caractérisée par des brûlures d'estomac ou une régurgitation acide, inclut l'œsophagite érosive ou le reflux négatif à l'endoscopie et peut être traitée empiriquement comme un RGOP, sans examens plus approfondis, pourvu qu'on n'observe aucune caractéristique alarmante. Les changements au mode de vie ne sont pas efficaces à l'égard de symptômes de RGOP fréquents ou graves. Les antiacides ou les inhibiteurs du récepteur $\mathrm{H}_{2}$ de l'histamine en vente libre sont efficaces pour certains patients atteints de symptômes de RGOP légers ou peu fréquents. Les inhibiteurs de la pompe à protons sont plus efficaces pour la cicatrisation et le soulagement des symptômes que les inhibiteurs du récepteur $\mathrm{H}_{2}$ de l'histamine. Leur efficacité est proportionnelle à leur capacité de réduire l'acidité intragastrique. La réponse au traitement initial, constitué d'un inhibiteur de la pompe à proton quotidien à moins que les symptômes soient légers et peu fréquents (moins de trois fois par semaine), devrait être évaluée au bout de quatre à huit semaines. Une médicothérapie d'entretien devrait être maintenue à la dose et à la fréquence les plus faibles nécessaires pour maintenir

Castroesophageal reflux disease (GERD) imposes an impor-

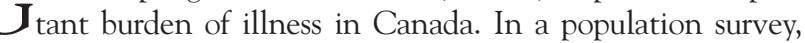
approximately $17 \%$ of Canadians reported heartburn in the preceding three months and 13\% reported moderate to severe symptoms occurring at least weekly (1). GERD significantly impairs quality of life (2-4), both in patients with erosive esophagitis and in those who have no endoscopic evidence of injury (endoscopy-negative reflux disease [ENRD]) (3,5). Although disease-related mortality is low, health-related quality of life (HRQL) is worse in patients with GERD than in patients with diabetes, hypertension, mild heart failure and arthritis (6).

Since the last Canadian GERD Consensus, held in 1996 (7), numerous studies have provided new evidence relevant to the management of GERD with increasing emphasis on symptombased management $(8,9)$, supported by greater recognition of the importance of ENRD. The role of investigations has evolved as a result of advances in the endoscopic assessment of erosive esophagitis severity (10-12), and a re-evaluation of the role of ambulatory $\mathrm{pH}$ monitoring (13). GERD therapy has also changed; in the realm of medical therapy, proton pump inhibitors (PPIs) have assumed greater importance, both at standard and higher doses, histamine $\mathrm{H}_{2}$-receptor antagonists ( $\left.\mathrm{H}_{2} \mathrm{RAs}\right)$ have become available as over-the-counter medications and the role of prokinetic agents has diminished. Antireflux surgery continues to evolve and new endoscopic therapies are under development. As a result of these advances, there is a need for a comprehensive, up-to-date, evidence-based review of GERD management to guide patients, physicians, payers and regulators, as well as the pharmaceutical and medical equipment industry, in their assessment of different strategies for diagnosis and initial and long-term treatment, including pharmacotherapy, endoscopic therapy and antireflux surgery.

The key areas addressed by the 2004 GERD Consensus Update were the prevalence and burden of GERD in Canada, the diagnosis of GERD (including the role of symptoms and investigations), initial and long-term treatment strategies and the management of GERD sequelae including Barrett's esophagus and esophageal cancer. The consensus dealt only with 'typical' esophageal manifestations of GERD. Noncardiac chest pain (NCCP) and possible extraesophageal manifestations of GERD such as laryngitis, hoarseness, dysphonia, cough, asthma and dental disease were not discussed in detail. Several pediatric gastroenterologists participated in the meeting but specific data in children and adolescents were not un soulagement des symptômes. Une opération antireflux représente une solution pour une petite proportion de patients. Il n'est pas nécessaire de procéder au dépistage systématique de l'infection à Helicobacter pylori avant d'entreprendre le traitement du RGOP. Le RGOP s'associe à l'épithélium de Barrett et à l'adocarcinome de l'œsophage, mais le risque de malignité est très faible. Le dépistage endoscopique de l'épithélium de Barrett peut être envisagé chez les adultes qui présentent des symptômes de RGOP depuis plus de dix ans. D'ordinaire, l'épithélium de Barrett et la dysplasie bénigne exigent une surveillance. La prise en charge endoscopique ou chirurgicale devrait être envisagée en présence d'une dysplasie ou d'une malignité grave confirmée.

CONCLUSIONS : Des études prospectives s'imposent pour examiner les facteurs de risques pertinents, d'un point de vue clinique, à l'apparition du RGOP et de ses complications, à la progression du RGOP avec ou sans traitement, aux stratégies optimales de prise en charge des symptômes classiques de RGOP chez des patients de première ligne et aux stratégies optimales de prise en charge en présence de symptômes non classiques de RGOP, d'épithélium de Barrett ou d'adénocarcinome œesophagien.

reviewed; we refer the reader to the North American Society for Pediatric Gastroenterology and Nutrition Clinical Practice Guidelines (14).

\section{METHODS}

Statements to define current understanding or positions relevant to GERD were developed according to generally accepted standards $(15,16)$ using a seven-step approach (Figure 1) to address the 37 pertinent criteria of validity $(16-21)$.

\section{Determination of need for updated guidelines}

The need for updated clinical practice guidelines on the management of adult patients with GERD was assessed by an initial review of the existing literature and current recommendations relevant to Canadian practice. This assessment revealed significant changes since the publication of the previous Canadian guidelines in 1997 (7), and a proposal to update those guidelines was, consequently, approved by the executive of the Canadian Association of Gastroenterology (CAG).

\section{Membership of the Consensus group}

A steering committee, selected in consultation with CAG, invited experts in the areas of GERD management, evidence-based medicine and continuing medical education to join a multidisciplinary group that comprised 23 voting participants, including Canadian and international gastroenterologists, endoscopists, family physicians and surgeons (Appendix). Nonvoting observers included physicians (members of CAG) and representatives from government (Health Canada), the pharmaceutical industry, and distributors and manufacturers of medical equipment (Appendix).

\section{Determination of clinically relevant issues}

The issues were identified by means of two needs assessments conducted in Canadian physicians: 44 primary care physicians from the Canadian Association of Primary Care Gastroenterology (CanGut) completed a paper-based questionnaire, while 86 specialists (81 of approximately 450 Canadian gastroenterologists and five surgeons) were polled using interactive, keypad-based voting in a large group setting. Issues identified by the needs assessments were then reviewed to determine whether they could be resolved with the existing knowledge base, were relevant to current practice, and were consistent with current GERD management strategies (16). Members of the steering committee then identified a number of relevant topics that were circulated electronically for review before the 


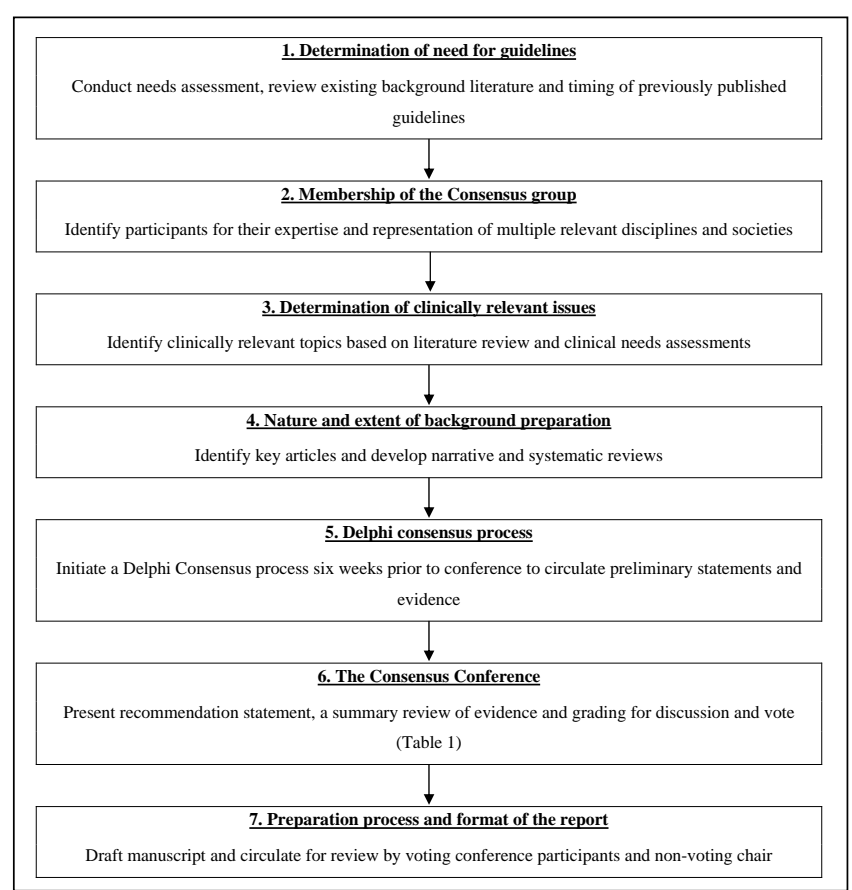

Figure 1) The adopted process of guideline development. Data from reference 16

meeting $(22,23)$; each topic was then used to generate a statement suitable for discussion and revision by the conference participants before undergoing a final vote on its acceptability.

\section{Nature and extent of background preparation}

Literature review methods for relevant articles included MEDLINE searches and manual searches of bibliographies of key articles published in English between 1966 and February 2004. Search terms included: "GERD", "erosive and non-erosive reflux esophagitis", "endoscopy-negative reflux disease", "alarm features", "ambulatory esophageal pH monitoring", "Barrett's esophagus", "dysplasia”, "healing”, "quality of life", "lifestyle modifications", "alginate", "antacid”, "histamine-receptor antagonist”, "proton pump inhibitor", "endoscopy”, "surgical therapy”, "economics", "guidelines" and "meta-analysis". Past reviews, meta-analyses and published consensus conferences were used to summarize older data. Narrative reviews were presented at the Consensus Conference before formal voting on the statements that had been identified for discussion at the meeting.

More than 720 articles were reviewed and the Delphi process identified 27 topics for discussion at the meeting. Statements that were identified by the Delphi process as being less controversial or of lower priority were put to a vote without formal discussion during the conference.

\section{Delphi Consensus process}

Each statement was graded to indicate the level of evidence available and the strength of the recommendation by using the classification system of the Canadian Task Force on the Periodic Health Examination (Table 1) (24). This classification system was developed to assess literature on therapy rather than literature on prognosis, diagnosis or definitions; the grading procedure was, therefore, modified for some statements, such as those on disease definition and prevalence (24).

\section{TABLE 1}

Categorization of evidence, classification of recommendations and voting schemata

\begin{tabular}{|c|c|}
\hline Qua & lity of evidence \\
\hline $\mathrm{I}$ & Evidence obtained from at least one properly randomized controlled trial \\
\hline II-1 & Evidence obtained from well-designed controlled trials without randomization \\
\hline II-2 & $\begin{array}{l}\text { Evidence obtained from well-designed cohort or case-control analytic } \\
\text { studies, preferably from more than one centre or research group }\end{array}$ \\
\hline II-3 & $\begin{array}{l}\text { Evidence obtained from comparisons between times or places with or } \\
\text { without the intervention, or dramatic results in uncontrolled experiments }\end{array}$ \\
\hline III & $\begin{array}{l}\text { Opinions of respected authorities, based on clinical experience, } \\
\text { descriptive studies or reports of expert committees }\end{array}$ \\
\hline Clas & ssification of recommendations \\
\hline A & There is good evidence to support the procedure or treatment \\
\hline B & There is fair evidence to support the procedure or treatment \\
\hline C & $\begin{array}{l}\text { There is poor evidence to support the procedure or treatment, } \\
\text { but recommendations may be made on other grounds }\end{array}$ \\
\hline $\mathrm{D}$ & There is fair evidence that the procedure or treatment should not be used \\
\hline $\mathrm{E}$ & There is good evidence that the procedure or treatment should not be used \\
\hline Votir & ing on the recommendations* \\
\hline $\bar{a}$ & Accept completely \\
\hline b & Accept with some reservation \\
\hline c & Accept with major reservation \\
\hline d & Reject with reservation \\
\hline e & Reject completely \\
\hline
\end{tabular}

${ }^{*}$ Accept statement where more than $50 \%$ of participants voted $a, b$ or $c$

\section{General organization}

A two-day Consensus Conference was held in March 2004, under the auspices of the CAG according to generally accepted principles $(15,16)$. At the Consensus Conference, data were presented and the statements and the grades attributed to evidence were discussed, modified if necessary, and voted on by each participant according to recognized criteria (Table 1) (9). The CAG secured unrestricted, multipartner funding from the Canadian Institutes of Health Research and industry sponsors, and it administered all aspects of the meeting. Statements of conflicts of interest were obtained from all voting participants (25).

\section{Preparation process and format of the report}

A working group drafted the manuscript, which was then reviewed by all voting conference participants and the nonvoting chairs, all of whom approved the final draft. It was then submitted to the Board of the CAG for approval and posted on the CAG Web site for review by the CAG membership before submission for peer review.

\section{STATEMENTS}

Each statement is followed by a brief summary, which indicates the quality of supporting evidence, a classification of the recommendation and the results of the participants' vote (Table 1). Statements that only defined terminology were not assigned a level of evidence. Statements marked with an asterisk $(*)$ were put to a vote without formal discussion during the conference (see 'Nature and extent of background preparation').

\section{IMPACT OF GERD}

Statement 1*: GERD is the most prevalent acid-related disorder in Canada (Level II-1, A; vote: a 86\%, b 14\%).

In a population survey of over 1000 Canadians, $17 \%$ reported 
heartburn in the preceding three months and 13\% reported moderate to severe symptoms occurring at least weekly (1). The prevalence of erosive esophagitis in the general population has not been well documented and was thought to be as low as $2 \%(26,27)$ although, in one report, endoscopy revealed esophagitis in $8.5 \%$ of 355 healthy volunteers (28). The prevalence of erosive esophagitis is probably between one-third to two-thirds among patients with reflux symptoms (29), suggesting a prevalence of $5 \%$ to $12 \%$ in the general population $(5,30-33)$. In a recent Canadian study (33), which excluded patients whose sole symptoms were heartburn or regurgitation, $37.8 \%$ of 1040 primary care patients with previously uninvestigated dyspepsia reported dominant symptoms of heartburn or regurgitation, and of these, $54.7 \%$ had erosive esophagitis; overall, $60.5 \%$ of the study patients had dominant reflux symptoms or endoscopic esophagitis. Thus, in Canadian patients with uninvestigated dyspepsia (symptoms consistent with an upper gastrointestinal, acid-related disorder), the most common condition was GERD presenting either as typical symptoms or with typical erosive esophagitis, with many others having typical GERD symptoms despite a normal endoscopy (ENRD).

Statement $2 *$ : GERD is associated with significant impairment of HRQL (Level I, A; vote: a 90\%, b 10\%).

GERD is associated with significant impairment of patients' HRQL $(1-4,34)$ both for patients with erosive esophagitis and those with ENRD $(3,5)$. In general, HRQL is reported to be worse in patients with GERD than in patients with diabetes, hypertension, mild heart failure or arthritis (6).

GERD is also associated with a loss of time from work and with decreased productivity $(35,36)$. A survey of 102 patients with GERD found that $41 \%$ reported some lost work productivity because of their disease (35); time off for physician visits and reduced productivity while at work were the most costly losses associated with GERD.

\section{DEFINITIONS}

Statement 3: GERD applies to individuals with reflux of gastric contents into the esophagus causing (a) symptoms sufficient to reduce quality of life and/or (b) esophageal injury (vote: a 96\%, b $4 \%$ ).

Statement 4*: Heartburn (a retrosternal burning sensation which may rise to the back of the throat) and acid regurgitation are the archetypal symptoms of GERD, which can be treated empirically without further investigation, provided there are no alarm features (Level I, A; vote: a 100\%).

Statement 5*: Heartburn-dominant uninvestigated dyspepsia applies to individuals who have symptoms, referable to the esophagus, or a reduced quality of life attributable to gastroesophageal reflux, in the absence of any prior investigations (Level III, A; vote: a $58 \%$, b 37\%, c 6\%).

Statement 6: ENRD applies to individuals with GERD who have a normal endoscopy (while off treatment) (vote: a 96\%, b 4\%).

GERD may manifest with symptoms, esophageal injury or both; if neither is present, the patient with increased acid exposure on esophageal $\mathrm{pH}$ monitoring may be considered to have nonpathological gastroesophageal reflux, but not GERD. As indicated above (statement 1), 30\% to $70 \%$ of patients with GERD symptoms have no esophageal abnormality at endoscopy (5,30-33); this may be because there is no, and never has been, esophageal damage; because previous erosions have healed spontaneously and are not evident at the time of endoscopy; or because the individual is taking, or has recently taken, effective antireflux medication $(9,32)$. Patients in the first category may be considered to have ENRD, while those in the other two categories should be considered to have erosive esophagitis, even if it is not evident at the time of investigation. Unfortunately, it is not clear when pharmacological therapy should be discontinued to ensure that a diagnosis of ENRD is accurate. Although erosive esophagitis recurs rapidly in a high proportion of patients after discontinuation of therapy, $20 \%$ to $30 \%$ may still be free of erosions for up to six months $(37,38)$. Patients with ENRD are, arguably, the most common subgroup of GERD patients and their symptoms will often respond to effective acid-suppressive therapy (39).

Because most patients with typical GERD symptoms (heartburn and regurgitation) neither undergo, nor require, investigation, one does not know whether they have erosive esophagitis; furthermore, unless they have received effective acid suppression therapy, one does not know whether their symptoms are acid-related and, hence, likely to be attributable to GERD. The term 'heartburn-dominant, uninvestigated dyspepsia' is, therefore, applicable to patients who present with reflux-like symptoms (with or without other dyspeptic symptoms referable to the upper gastrointestinal tract) before they undergo investigation or receive therapy. The Consensus group felt that it was reasonable to diagnose heartburn-dominant uninvestigated dyspepsia as GERD (encompassing both ENRD and erosive esophagitis), and manage it accordingly. The symptom-based approach to diagnosing GERD is a reasonable strategy despite the fact that some patients may prove to have been categorized incorrectly as having GERD on the grounds that antireflux treatment is ineffective (39) or that endoscopy reveals other lesions such as peptic ulceration (33).

The term 'ENRD' used in this document is synonymous with the terms 'nonerosive reflux disease' and 'symptomatic GERD' (40); all three terms are applicable to patients who have typical reflux symptoms and a normal esophagus at endoscopy.

While heartburn and regurgitation are the dominant symptoms of GERD, they frequently coexist with other symptoms such as epigastric pain, epigastric burning and nausea. Other esophageal manifestations of GERD including chest pain and dysphagia, and extraesophageal manifestations including cough, sore throat, hoarseness, shortness of breath and wheezing are less prevalent in GERD patients $(41-43)$ and it is not clear if some of these are 'atypical' GERD symptoms or ancillary symptoms unrelated to GERD.

\section{ASSESSING SEVERITY}

Statement 7*: GERD symptom severity, incorporating the frequency, intensity and duration of symptoms, is defined by the extent to which the sufferer indicates that it has an adverse effect on his or her daily activities and HRQL (Level II-3, B; vote: a 59\%, b 32\%, c 9\%).

Statement 8*: GERD severity is determined by the severity and frequency of the associated symptoms or by the presence and extent of reflux-related lesions such as esophageal erosions, ulcers, 
hemorrhage, strictures or columnar metaplasia (Barrett's epithelium) (Level I, A; vote: a 76\%, b 19\%, c 0\%, d 0\%, e 5\%).

Statement 9*: In the context of symptomatic management of GERD, 'mild disease' is applicable to patients who have symptoms that are infrequent (fewer than three times/week), of low intensity and short duration, and that have minimal long-term effect on the patient's activities of daily living or HRQL. The terms 'moderate disease' or 'severe disease' are applicable to patients who have more frequent, intense or prolonged symptoms that have a significant effect on the patient's daily activities or HRQL (vote: a 55\%, b $45 \%$ ).

The severity of GERD should be assessed with respect to the impact of symptoms on an individual's daily activities and HRQL. The effect of GERD on HRQL is dependent primarily on the severity of symptoms, which incorporates frequency, intensity and duration. Impairment of HRQL is very similar for patients with erosive esophagitis and those with ENRD $(3,5,31)$. However, more individuals with severe GERD symptoms report a loss of productivity compared with those with mild symptoms (36). GERD can also be defined by the severity of endoscopic findings (12), because severe erosive esophagitis responds less well to antireflux treatment and relapses more quickly than does mild esophagitis (44-47).

\section{DIAGNOSIS}

Statement 10*: In clinical practice, a diagnosis of GERD can be made without investigation, based on the presence of the typical symptom of heartburn, with or without regurgitation (Level II-1, A; vote: a $59 \%$, b 27\%, c 9\%, e 5\%).

Statement 11*: A diagnosis of GERD can be made regardless of the frequency or severity of the individual's GERD-related symptoms (Level II-2, A; vote: a 50\%, b 27\%, c 5\%, d 14\%, e 5\%).

There is general consensus that patients with dominant symptoms of heartburn or regurgitation can be assigned a clinical diagnosis of GERD and treated without the need for investigations $(8,9,48)$. It has been difficult to document the predictive value of symptoms because there is no accepted gold standard for the diagnosis of GERD, although the use of latent class analysis or Bayesian analysis to integrate the results of three or more independent investigations may, in the future, provide an acceptable gold standard (49). Although patients with heartburn and regurgitation who do not respond to standard antireflux therapy (39) may have functional heartburn rather than GERD $(50,51)$, the majority of the Consensus group felt that heartburn-dominant uninvestigated dyspepsia or ENRD could be treated, initially, as GERD. This approach is supported by data from two surveys of primary care patients with uninvestigated dyspepsia, which indicated that symptoms of epigastric pain, heartburn and regurgitation cluster together, while bloating, belching and nausea form a distinct cluster $(33,52)$. Dominant symptoms of heartburn or acid regurgitation have a high specificity ( $89 \%$ and $95 \%$, respectively) but low sensitivity (38\% and 6\%) for GERD as defined by abnormal acid exposure on $24 \mathrm{~h} \mathrm{pH}$ monitoring (53). Using a questionnaire, the presence of heartburn (defined as a "burning feeling in the stomach or lower chest rising up to the neck") had a sensitivity of $73 \%$ and a specificity of $43 \%$ compared with abnormal $24 \mathrm{~h}$ esophageal $\mathrm{pH}$ monitoring or erosive disease on endoscopy, and was predictive of symptom resolution during treatment with omeprazole $20 \mathrm{mg}$ (54). However, $\mathrm{pH}$ monitoring or endoscopy may be normal in GERD and may, therefore, underestimate the accuracy of symptoms for diagnosis (13). In fact, $24 \mathrm{~h} \mathrm{pH}$ monitoring is no longer considered to be the gold standard, because it lacks the high sensitivity previously claimed, for the diagnosis of GERD (13). Overall, current 'objective' diagnostic tests for GERD are invasive, costly and insufficiently reliable; furthermore, they are not readily available to most physicians in Canada.

In general, neither symptom severity nor frequency alone constitutes a diagnostic criterion for GERD; for example, reflux-related NCCP is consistent with a diagnosis of GERD even if symptoms are infrequent. On the other hand, mild, infrequent heartburn that does not affect quality of life is not, on its own, considered to be sufficient for a definitive diagnosis of GERD.

It has been suggested that a symptomatic response to PPI therapy can be used for the diagnosis of GERD. A PPI test (one to two weeks of high-dose PPI therapy) has demonstrated a sensitivity of $80 \%$, a specificity of $57 \%$, and positive and negative predictive values comparable with $\mathrm{pH}$ monitoring (55-57). However, a PPI test has not been shown to be superior to a trial of standard therapy (58). There was, therefore, consensus that a short-term PPI test was unhelpful before initiating therapy for typical reflux symptoms, because a 'negative' PPI test may deprive many patients of the more prolonged four to eight week course of therapy needed to relieve symptoms (58). A PPI test has high sensitivity and specificity for identifying patients with acid-related NCCP occurring at least three times weekly $(59,60)$, and the one-week test is cost-effective compared with standard investigations $(59,61)$.

\section{INVESTIGATIONS}

\section{Alarm features}

Statement 12*: Alarm features in the presence of GERD symptoms include vomiting, evidence of gastrointestinal tract blood loss, anemia, involuntary weight loss, dysphagia or chest pain (Level III, A; vote: $a 68 \%, b 23 \%$, c $5 \%, d 5 \%)$.

Statement 13: In patients with GERD, dysphagia should be investigated if it does not completely resolve with adequate PPI therapy (two to four weeks) (Level III, C; vote: a 70\%, b 30\%).

Statement 14: There is no age threshold (eg, 50 years) that is, by itself, an indication for further investigation for GERD (Level II-2, B; vote: $a 91 \%, b 9 \%$ ).

Recent guidelines for the management of dyspepsia and GERD have identified alarm features, including persistent vomiting, symptoms or signs of gastrointestinal bleeding, unexplained or involuntary weight loss, dysphagia, choking (acid-induced coughing, shortness of breath or hoarseness) and chest pain, which require prompt investigation $(8,9,48,62)$. This should not be taken to imply that all patients with alarm features require endoscopy; if chest pain is present, cardiac causes should be excluded first and, even for patients with NCCP, investigations other than endoscopy may be appropriate. However, there are few Level I data on which to base these recommendations and there are even fewer data to indicate whether they should always be considered as alarm features. A history of dysphagia, for example, can often be elicited in patients with erosive esophagitis and, if it is mild, it often resolves with acid suppressive therapy (63). On the other hand, if solid food dysphagia is the primary symptom, it should 
be considered an alarm feature suggesting peptic stenosis, stricture, esophageal ring or web or esophageal malignancy, and investigation should be expedited, particularly if the dysphagia is progressive or if it does not respond within two to four weeks to adequate PPI therapy.

Although the prevalence of esophageal cancer is higher in individuals over 50 years of age, it is not high enough to justify prompt investigation in all patients who present with GERD symptoms (uninvestigated GERD or heartburn-dominant uninvestigated dyspepsia) for the first time over the age of 50 years (33). Statement 14 is not intended to preclude investigation for Barrett's esophagus in patients over the age of 50 years (see statements 52 to 58 ), it merely indicates that patients with GERD symptoms should not require investigation solely because they are over the age of 50 years.

\section{Endoscopy}

Statement 15*: Endoscopy is not required to make a diagnosis of GERD (Level I, A; vote: a 91\%, b 9\%).

Statement 16: The role of endoscopy in patients with GERD symptoms is to investigate atypical or alarm features and to detect Barrett's esophagus (Level III, B; vote: a 100\%).

Statement 17*: The severity of erosive esophagitis is determined endoscopically by the presence and extent of reflux-related 'mucosal breaks' (erosions or ulcers) as defined by the Los Angeles classification (Level I, A; vote: a 82\%, b 14\%, c 0\%, d $0 \%$, e $5 \%$ ).

Statement 18*: If a patient with GERD symptoms is to undergo endoscopy in clinical practice, it is not generally necessary to discontinue antisecretory therapy before the procedure (Level II-3, B; vote: $a 68 \%, b 18 \%, c 5 \%, d 9 \%)$.

Statement 19*: Esophageal histology is not required to diagnose GERD in a patient with typical symptoms (Level II-2, B; vote: a $73 \%, b 27 \%$ ).

Up to $70 \%$ of patients with symptoms of GERD have no endoscopic evidence of esophagitis and are considered to have ENRD (5,30-33). Thus, although it is highly specific (greater than $90 \%$ ), endoscopy has lower sensitivity (40\% to $60 \%$ ) $(9,64)$ and is not essential for a diagnosis of GERD. Endoscopy should not, therefore, be considered a prerequisite for any form of pharmacological acid suppression therapy.

Endoscopy is indicated for the majority of patients who present with alarm symptoms referable to the upper gastrointestinal tract (statement 12) (10); under these circumstances, it is useful for the detection of GERD complications such as ulceration, strictures, Barrett's epithelium and esophageal malignancy. The role of endoscopy in the investigation of atypical symptoms is ill defined; it may reveal changes that would support a diagnosis of GERD but a normal endoscopy does not rule out GERD. If endoscopy is performed to identify Barrett's epithelium, the patient should be taking effective antisecretory therapy because it can be difficult to distinguish dysplasia from chronic inflammatory and regenerative changes caused by esophageal injury (65). Erosive esophagitis is best identified by endoscopy, although in clinical practice it is generally unnecessary to differentiate between erosive esophagitis and ENRD. However, in clinical trials in which it is necessary to differentiate erosive esophagitis from ENRD, acid suppression therapy is generally discontinued at least two weeks before endoscopy, recognizing that the time to esophagitis relapse may be much longer in many patients $(37,38,46,66)$. Although there are many endoscopic esophagitis classification schemes, the consensus favoured the Los Angeles system because of its extensive validation for grading the endoscopic severity of erosive esophagitis and its widespread use (Table 2) (10-12,67).

Mucosal biopsies are essential to confirm Barrett's epithelium and to detect dysplasia, but not to diagnose GERD if typical mucosal breaks are present at endoscopy (68). Biopsies or follow-up endoscopies are recommended for deeply ulcerated, extensively eroded circumferential lesions or grossly irregular lesions to distinguish inflammatory ulceration from an ulcerated sessile malignancy. Biopsies are also indicated if a diagnosis other than reflux disease (eg, eosinophilic esophagitis) is suspected. The role of esophageal biopsy for the diagnosis of GERD in ENRD patients with typical symptoms and a normal endoscopy is uncertain. Recent studies $(69,70)$ have confirmed earlier histological findings of basal hyperplasia and papillary elongation in GERD patients (71), and have also shown that these abnormalities, as well as intercellular space dilation, tend to diminish with PPI therapy (72-74), but histology remains unproven as a means of diagnosing GERD. The role of a 'once in a lifetime' endoscopic screening for Barrett's epithelium is discussed under the section on Barrett's epithelium (statements 52 and 53).

\section{Ambulatory $\mathrm{pH}$ monitoring}

Statement 20*: In adult clinical practice, ambulatory esophageal $\mathrm{pH}$ monitoring is indicated primarily for the investigation of atypical or persistent symptoms despite appropriate therapy (Level II-1, B; vote: $a 77 \%, b 23 \%)$.

Ambulatory $24 \mathrm{~h}$ esophageal $\mathrm{pH}$ monitoring has generally been considered the gold standard to detect 'pathological' reflux, with good sensitivity (77\% to $100 \%)$ and specificity $(85 \%$ to $100 \%)$ in patients with endoscopic esophagitis $(13,75)$. However, it is less reliable for the diagnosis of ENRD with reported sensitivities of $0 \%$ to $71 \%$, and specificities of $85 \%$ to $100 \%(13,75)$ versus symptom-based diagnoses. It may be used to quantify esophageal acid exposure but there is poor correlation between measures of acid exposure (eg, time with esophageal $\mathrm{pH}$ below 4.0; DeMeester score) and reflux-related symptoms, esophageal sensitivity or response to acid suppressive therapy. Furthermore, esophageal $\mathrm{pH}$ monitoring is impractical in routine practice because it is expensive, cumbersome and not widely available. Esophageal $\mathrm{pH}$ monitoring may be appropriate to document abnormal acid exposure in patients with a normal endoscopy who are being considered for surgery; to evaluate patients who are refractory to medical or surgical antireflux therapy; to evaluate patients with atypical GERD symptoms such as NCCP; or to evaluate possible extraesophageal manifestations such as hoarseness, cough or asthma (13). The use of a $\mathrm{pH}$-sensitive telemetry capsule affixed to the esophageal epithelium (Bravo, Medtronic, USA) may improve patient tolerability but experience with this device is limited and, because the capsule is not reusable, it may prove to be too expensive for widespread use in Canada. The role of monitoring bile reflux (bilirubin detector) or nonacid reflux (esophageal impedance monitoring) in the management of GERD remains unclear. 
TABLE 2

The Los Angeles classification system for the endoscopic assessment of esophagitis

\begin{tabular}{l} 
Grade $\quad$ Definition \\
\hline A $\quad$ One or more mucosal breaks no longer than $5 \mathrm{~mm}$, none of which \\
extends between the tops of the mucosal folds \\
B $\quad$ One or more mucosal breaks more than $5 \mathrm{~mm}$ long, none of which \\
extends between the tops of two mucosal folds \\
C Mucosal breaks that extend between the tops of two or more mucosal \\
folds, but which involve less than $75 \%$ of the esophageal \\
circumference \\
Mucosal breaks which involve at least $75 \%$ of the esophageal \\
circumference
\end{tabular}

Data from references $10-12$

The sensitivity and specificity of barium radiology are insufficiently high for it to be useful for the diagnosis or management of GERD (76).

\section{INITIAL THERAPY}

Statement $21 *$ : Over-the-counter medications, including alginates, antacids and low-dose $\mathrm{H}_{2} \mathrm{RAs}$, are safe and effective for symptom management in individuals with mild GERD symptoms (Level I, A; vote: a $82 \%, b 18 \%)$.

Statement 22*: Lifestyle modifications, with or without over-thecounter antacids or $\mathrm{H}_{2} \mathrm{RAs}$, are not effective for the management of frequent or severe GERD symptoms (Level II-2, A; vote: a $68 \%$, b $27 \%$, c $5 \%$ ).

Over-the-counter medications including alginates, antacids and low-dose $\mathrm{H}_{2}$ RAs are safe and effective for the management of mild and infrequent GERD symptoms (statement 9) in many individuals $(9,77)$, but they have limited efficacy in patients with more severe GERD, including erosive esophagitis, complications or symptoms that reduce HRQL $(8,9,78)$. Although all patients should be educated about factors that may worsen their GERD symptoms, lifestyle modifications alone generally provide inadequate relief for most GERD patients. There are few data on the efficacy of lifestyle modifications in patients with mild GERD, but clinical experience suggests they may be beneficial if there are obvious dietary or pharmacological precipitants, or if obesity, smoking or excessive alcohol use is present.

Statement 23: PPIs are superior to $\mathrm{H}_{2} \mathrm{RAs}$ for the reduction of heartburn and healing of esophagitis (Level 1, A; vote: a 100\%).

Statement 24: The effectiveness of PPIs and $\mathrm{H}_{2} \mathrm{RAs}$ for the healing of esophagitis is proportional to their ability to reduce intragastric acidity (Level 1, A; vote: a 91\%, b 9\%).

Statement 25: Initial therapy for GERD symptoms should be a once-daily PPI unless symptoms are mild and infrequent (fewer than three times per week) (Level 1, A; vote: a 74\%, b 26\%).

Throughout the discussions on PPI therapy, standard PPI doses were defined as the daily doses approved in Canada for healing erosive esophagitis: esomeprazole $40 \mathrm{mg}$, lansoprazole $30 \mathrm{mg}$, omeprazole $20 \mathrm{mg}$, pantoprazole $40 \mathrm{mg}$ and rabeprazole $20 \mathrm{mg}$ (Table 3). A meta-analysis of treatment trials, derived from 43 articles in 7635 patients with erosive esophagitis, showed
TABLE 3

Standard once-daily doses of available proton pump inhibitors

\begin{tabular}{lc}
\hline Proton pump inhibitor & Daily dose \\
\hline Esomeprazole (Nexium)* & $40 \mathrm{mg}$ \\
Lansoprazole (Prevacid) $^{\dagger}$ & $30 \mathrm{mg}$ \\
Omeprazole (Losec)* $^{\star}$ & $20 \mathrm{mg}$ \\
Pantoprazole (Pantoloc) $^{\ddagger}$ & $40 \mathrm{mg}$ \\
Rabeprazole (Pariet) $^{\S}$ & $20 \mathrm{mg}$
\end{tabular}

*AstraZeneca, Canada; †Abbott Laboratories, Canada; ${ }^{\ddagger}$ Altana Pharma/ Solvay Pharma, Canada; §Janssen-Ortho, Canada. Optimal dosing is $30 \mathrm{~min}$ to 60 min before breakfast or supper

that PPIs heal esophagitis more rapidly and in more patients than do $\mathrm{H}_{2} \mathrm{RAs}$, with overall (two- to 12 -week) healing rates of $83.6 \%$ (95\% CI $79.1 \%$ to $88.1 \%$ ) and $51.9 \%$ (95\% CI $46.9 \%$ to $56.9 \%)$, respectively, compared with placebo $(28.2 \%$; $95 \%$ CI $19.2 \%$ to $37.2 \%$ ) (79). Similarly, a meta-analysis of 13 trials of empirical therapy in 3433 GERD patients and 2520 ENRD patients (39) indicated that PPIs were almost twice as effective as $\mathrm{H}_{2} \mathrm{RAs}$ in the empirical treatment of GERD and 20\% more effective in the treatment of ENRD (RR 0.55 [95\% CI 0.44 to 0.68 ] and 0.81 [95\% CI 0.70 to 0.95], respectively) (39).

GERD severity is related to the degree and duration of esophageal acid exposure (80); the duration of esophageal acid exposure (time during which intraesophageal $\mathrm{pH}$ is below 4.0) correlates directly with the degree of mucosal injury (81-84) and severity of symptoms (85). Treatments that prolong gastric acid suppression (time during which gastric $\mathrm{pH}$ is over 4.0) are associated with faster symptom relief and higher healing rates $(79,86,87)$. PPIs are significantly more effective than $\mathrm{H}_{2} \mathrm{RAs}$ in achieving and sustaining an intragastric $\mathrm{pH}$ above 4.0 $(80,88)$; they also produce greater healing and symptom relief than do $\mathrm{H}_{2} \mathrm{RAs}$ in patients with confirmed GERD $(79,89)$, and greater symptom relief in patients with ENRD (39) or uninvestigated heartburn-dominant dyspepsia (90). In most studies, PPIs were compared with standard dose $\mathrm{H}_{2} \mathrm{RAs}$ but double dose $\mathrm{H}_{2}$ RAs were also less effective than standard dose PPIs (Table 3 ) for healing erosive esophagitis $(91,92)$, and double dose ranitidine was ineffective in patients who had not previously responded to a six-week course of standard dose ranitidine (93).

In general, $24 \mathrm{~h}$ intragastric $\mathrm{pH}$ studies suggest that standard dose omeprazole, lansoprazole, pantoprazole and rabeprazole are similar with respect to their effect on the duration of the $24 \mathrm{~h}$ period during which gastric $\mathrm{pH}$ remains above 4.0 (94-101). However, $24 \mathrm{~h}$ intragastric $\mathrm{pH}$ studies suggest greater suppression of gastric acidity with esomeprazole $40 \mathrm{mg}$ compared with lansoprazole $30 \mathrm{mg}(102,103)$, omeprazole $20 \mathrm{mg}(103,104)$ and $40 \mathrm{mg}(105)$, pantoprazole $40 \mathrm{mg}$ $(103,106)$ and rabeprazole $20 \mathrm{mg}(102,103)$, although these differences do not necessarily lead to a difference in esophageal acid exposure (107). There also appears to be a dose-response effect for some PPIs $(108,109)$. Corresponding to the $\mathrm{pH}$ results, the results of meta-analyses $(89,110)$ suggest that standard dose omeprazole, lansoprazole, pantoprazole and rabeprazole are equivalent to each other with respect to healing esophagitis. While these meta-analyses and the largest available randomized controlled studies suggest that esomeprazole $40 \mathrm{mg}$ produces somewhat higher four- and eight-week healing 
rates than standard dose omeprazole $(45,47,110)$, lansoprazole (44) or pantoprazole (111), particularly in more severe (Los Angeles grades $\mathrm{C}$ and $\mathrm{D}$ ) erosive esophagitis, overall differences in healing proportions at eight weeks are small, ranging from just over $3 \%(44,111)$ to just over $6 \%(45,47)$. Furthermore, although the differences are statistically significant, their clinical relevance is debated and the results have not been replicated consistently in other studies (112).

The proportion of patients reporting symptom relief is somewhat lower for those with ENRD than for those with erosive esophagitis (113); furthermore, higher PPI doses do not appear to elicit a greater response in $\operatorname{ENRD}(114,115)$.

The Consensus group made no recommendations with respect to the choice of PPI for initial or long-term therapy, noting that factors such as cost and availability were also important considerations. However, there was agreement that the clear superiority of the PPIs over $\mathrm{H}_{2} \mathrm{RAs}$ (with absolute differences in healing rates of $30 \%$ to $40 \%$ ) was sufficient to support the use of PPIs as initial therapy for all patients in whom symptoms have a significant impact on quality of life. In a study comparing step-up and step-down treatment strategies, initial PPI therapy provided faster symptom relief than initial $\mathrm{H}_{2} \mathrm{RA}$ therapy, and continued PPI therapy provided better heartburn relief than step-down to an $\mathrm{H}_{2} \mathrm{RA}$, while step-up to a PPI provided better heartburn relief than continued $\mathrm{H}_{2} \mathrm{RA}$ therapy (116). Given the excellent safety profile of PPIs and their superior efficacy, there is generally no justification, other than cost or intolerance to PPIs, to use an $\mathrm{H}_{2} \mathrm{RA}$ as initial therapy for GERD unless the patient's symptoms are mild or infrequent (see Economics section).

Statement 26*: The symptomatic response to an initial course of antisecretory therapy should be assessed at four to eight weeks (Level II-1, B; vote: a 77\%, b 23\%).

An adequate course of therapy is at least four to eight weeks. In a study comparing one-week courses of once-daily or twice-daily PPI therapy (PPI test, statements 10,11) with a four-week standard dose course, the response at one week was highly predictive (positive predictive values $96.1 \%$ and $96.3 \%$, respectively) of a good outcome at four weeks, but negative predictive values were low $(28.3 \%$ and $32.7 \%$, respectively) and almost $15 \%$ of patients who did not respond at one week did respond at four weeks (58). Further improvement in response rates was also seen as acid suppression therapy extended from four weeks to eight weeks in patients with erosive esophagitis (healing rates $66 \%$ to $81 \%$ and $75 \%$ to $95 \%$, at four and eight weeks, respectively) $(79,89,110,111,117)$, and the proportion of patients achieving complete resolution of heartburn-dominant uninvestigated dyspepsia increased progressively from four to 16 weeks (90). Clinical assessment of symptoms and quality of life at four to eight weeks is adequate for routine follow-up; endoscopy may be considered but, in general, only for patients with symptoms refractory to PPI therapy or those who develop new or worsening symptoms while on therapy. Failure to respond at eight weeks is not necessarily an indication for specialist referral or endoscopy, because the proportion of responders may increase after this time.

Statement 27: Twice-daily PPI therapy is not generally required as initial therapy for typical GERD symptoms (Level 1, A; vote: a 100\%).
Statement 28: Twice-daily, standard dose PPI therapy may be used for patients who have severe symptoms despite standard once-daily PPI therapy (Level II-3, B; vote: a 91\%, b 9\%).

Statement 29: Twice-daily, standard dose PPI therapy may be used for patients who have severe esophagitis (LA Grade C or D, or stricture) (Level I, B; vote: a 96\%, b 4\%).

There are few data documenting an increase in healing or symptom relief for double-dose PPI therapy compared with standard dose therapy (Table 3 ) in patients with typical GERD $(118,119)$; however, reports that, for example, double dose pantoprazole $(80 \mathrm{mg}$ ) was comparable with single dose pantoprazole $(40 \mathrm{mg}$ ) have not generally been powered to detect differences of less than $10 \%$ between treatment arms (117). Similarly, symptom response rates at one week for patients with uninvestigated dyspepsia, including heartburn-dominant symptoms, were comparable for esomeprazole $40 \mathrm{mg}$ once daily and esomeprazole $40 \mathrm{mg}$ twice daily (58). Half dose PPI therapy (eg, esomeprazole $20 \mathrm{mg}$, lansoprazole $15 \mathrm{mg}$, omeprazole $10 \mathrm{mg}$, pantoprazole $20 \mathrm{mg}$ or rabeprazole $10 \mathrm{mg}$ daily) is less effective than standard dose therapy for acute treatment in erosive esophagitis and ENRD $(32,114,120-122)$ and is not generally recommended for initial therapy.

Conversely, doubling the dose of a PPI reduced esophageal acid exposure in patients in whom single dose therapy was not adequate $(100,123)$. In patients with complicated or atypical GERD, esophageal acid exposure was normalized in all patients with lansoprazole but, of those, 35\% required a double daily dose $(60 \mathrm{mg})(100)$. In a similar study, persistently abnormal reflux at esophageal $\mathrm{pH}$ monitoring was seen in $29 \%$ of patients receiving lansoprazole $30 \mathrm{mg}$ once daily and $68 \%$ of those receiving omeprazole $20 \mathrm{mg}$ once daily, but was normalized in all patients after doubling the respective PPI doses (123). Data from pH studies support splitting the double dose and administering it twice daily, before breakfast and supper, rather than once daily (124-126). There is little clinical evidence to support the use of double dose or twicedaily PPI therapy for initial therapy (58). However, several trials have shown that a proportion of patients who had not responded to standard dose PPI therapy experienced symptom relief with double dose PPI or a longer duration of therapy $(90,118,127)$.

Twice daily, standard dose, PPI therapy is used in patients with NCCP or extraesophageal manifestations of GERD but these data were not reviewed formally by the Consensus group.

Statement 30*: Prokinetic or promotility agents are not recommended, either alone or in conjunction with antisecretory agents, for the routine initial treatment of GERD (Level II-1, C; vote: a 95\%, b 5\%).

A systematic review considered cisapride to be effective for mild-to-moderate GERD in adults (128) but not for GERD in children (129). As empirical therapy for GERD, cisapride was not superior to placebo, and for ENRD, PPIs were superior to cisapride (130). However, concerns about the methodological quality and publication bias have been raised $(79,129)$, and cisapride is no longer generally available. Domperidone produced little or no symptomatic improvement compared with placebo (131-133); in small studies, metoclopramide was more effective than placebo (134) but less effective than ranitidine $(135,136)$. 
There are very few data on the efficacy of supplementary prokinetics in conjunction with PPI therapy; the addition of cisapride to standard dose PPI therapy did not result in significant increases in healing rates or symptom relief after either four or eight weeks of treatment $(137,138)$, and the combination of domperidone plus ranitidine showed no benefit over ranitidine alone (139). Omeprazole is twice as effective as the combination of ranitidine plus metoclopramide or ranitidine alone for symptom improvement and healing (140-142), with no significant differences between ranitidine and the combination group (140). In addition, metoclopramide is associated with substantial side effects compared with standard antisecretory therapy, which limits its use $(140,142-144)$.

\section{LONG-TERM THERAPY}

Statement 31*: 'Continuous' medical maintenance therapy is defined as the daily intake of a medication for an indefinite period to prevent or minimize recurrent reflux-related symptoms or injury to the esophagus (vote: a 91\%, b 9\%).

Statement 32*: 'Intermittent' medical maintenance therapy is defined as the daily intake of a medication for a predetermined, finite period (usually two to eight weeks) to produce resolution of refluxrelated symptoms or healing of esophageal lesions following relapse of the individual's condition (vote: $a 86 \%, b 9 \%, c 5 \%$ ).

Statement 33*: 'On-demand' medical therapy is defined as the daily intake of a medication for a period sufficient to achieve resolution of the individual's reflux-related symptoms; following symptom resolution, the medication is discontinued until the individual's symptoms recur, at which point, medication is again taken daily until the symptoms resolve (vote: a 86\%, $b$ 14\%).

Although there are no standardized definitions of continuous, intermittent and on-demand $(21,145-150)$ therapy, the above definitions are consistent with those used in many clinical trials and may be appropriate for interpretation of their results, and the development of future clinical studies. It may be argued that intermittent therapy is a 'physician-driven' strategy, whereas on-demand therapy is 'patient driven'. Although clinical experience suggests that many patients take their medication prophylactically to prevent the occurrence of reflux symptoms, this pattern of usage is not included explicitly in the definition of on demand therapy used for clinical studies.

Statement 34*: The prime aim of long-term GERD therapy is symptom abolition or control sufficient to normalize the individual's HRQL (Level III, A; vote: a 82\%, b 14\%, c 5\%).

The primary aim of long-term management of patients with GERD is the control of symptoms and improvement of quality of life $(149,151)$. Because the risk of recurrent endoscopic erosions is extremely high without maintenance therapy $(149,152-154)$, long-term therapy is recommended for erosive esophagitis with the aim of preventing recurrent esophageal injury or mucosal breaks, in addition to complications such as stricture (155-159), hemorrhage, ulceration or Barrett's epithelium. However, the group recognized the lack of evidence that PPI therapy prevents the development or progression of Barrett's epithelium.

Statement 35: An individual whose reflux symptoms have responded well to standard dose PPI therapy may discontinue medication to confirm the need for ongoing therapy (Level II-3, C; vote a 83\%, b 17\%).
Statement 36*: Long-term maintenance therapy should be given at the lowest dose and frequency that is sufficient to achieve optimal control of the patient's symptoms (Level III, B; vote: a 71\%, b $10 \%, c 10 \%, d 5 \%$, e $5 \%)$.

Statement 37: On-demand acid suppression therapy is a reasonable long-term medical strategy for selected patients with GERD (Level I, B; vote a 55\%, b 45\%).

Some patients will not require continuous, daily, standard dose therapy for long-term management, but most patients will require some form of maintenance therapy. After discontinuation of therapy, $70 \%$ to $100 \%$ of patients with esophagitis $(37,38,160,161)$ and approximately $75 \%$ of patients with ENRD (31) will relapse within six months.

Half dose PPI therapy is sufficient to maintain endoscopic remission in about 35\% to $95 \%$ of patients with erosive esophagitis $(37,38,46,66,160-163)$. Similarly, half dose, ondemand PPI therapy produces acceptable symptom control in $83 \%$ to $92 \%$ of ENRD patients $(21,146,148)$ who have responded previously to acute PPI therapy; however, half dose omeprazole (10 mg daily) is less effective than standard dose omeprazole (20 mg daily) (146), although half dose esomeprazole (20 mg daily) was comparable with standard dose esomeprazole (40 mg daily) (21,146). Although most patients with more severe symptoms or esophagitis require ongoing daily, standard dose therapy to maintain healing and symptom relief $(160,164)$, it was agreed that patients should be maintained on the lowest dose of therapy which was sufficient to provide adequate symptom relief. This presupposes that patients' symptom status will be reviewed to ensure that symptom control is adequate from the patient's standpoint. On-demand therapy may be acceptable because esophagitis recurrence, in the absence of symptoms, occurs in fewer than $9 \%$ of patients (160). However, because the majority of studies have been conducted in ENRD patients, there are insufficient data to recommend on-demand maintenance therapy for patients with erosive esophagitis.

There appears to be a dose-response relationship for each of the PPIs (Table 3) in maintenance therapy for erosive esophagitis, presumably related to the degree of acid suppression produced by each treatment regimen. However, the doseresponse relationship is less evident for ENRD partly, perhaps, because of difficulty in defining adequate symptom control and partly because there seems to be a ceiling effect such that higher degrees of acid suppression do not appear to be more effective after four weeks of therapy.

Standard dose PPIs are superior to full dose and half dose $\mathrm{H}_{2} \mathrm{RAs}$ for maintaining remission of erosive esophagitis (160). Although some studies suggest that, for maintenance therapy, half dose PPIs are equivalent to standard dose PPIs for erosive esophagitis $(37,38,66,162,163,165-167)$ and $\operatorname{ENRD}(21,148)$, others indicate higher remission rates with standard dose PPIs than with half or lower dose PPIs both for erosive esophagitis $(37,38,160,161,168-170)$ and ENRD (146). In a large study comparing two half dose therapies, esomeprazole $20 \mathrm{mg}$ daily was superior to lansoprazole $15 \mathrm{mg}$ daily in preventing recurrent esophagitis (46). Although on-demand therapy is effective in ENRD patients, the role of 'alternate day' or 'weekend' therapy in erosive esophagitis is unclear. Omeprazole (20 mg for three days/week or $20 \mathrm{mg}$ on weekends) was inadequate for maintaining endoscopic remission compared with daily omeprazole $20 \mathrm{mg}(150,160)$; lansoprazole $30 \mathrm{mg}$ on alternate 
days was less effective than lansoprazole $15 \mathrm{mg}$ daily for maintaining symptom relief although it was equally effective for maintaining healing (167). Overall, half dose PPI therapy is effective for some patients but a proportion will require full dose, or higher-dose maintenance PPI therapy $(127,171)$; this has primarily been documented for erosive esophagitis rather than ENRD. Noncontinuous PPI therapy is effective for ENRD but its role in erosive esophagitis remains uncertain.

Statement 38*: Long-term PPI therapy has not been associated with any clinically significant adverse events (Level II-2, A, vote: a $73 \%, b 27 \%$ ).

Long-term PPI use is supported by experience of millions of patient-years of therapy, and a review of omeprazole use for up to 11 years confirmed the safety of PPIs on the gastric mucosa $(172,173)$. Similarly, long-term data from one to five years of use support the safety of esomeprazole (174), lansoprazole $(175,176)$, pantoprazole $(162,177,178)$ and rabeprazole (179). Current evidence suggests that prolonged gastric acid suppression with PPIs rarely, if ever, produces adverse events or clinically significant drug interactions $(174,180$ 182). Diarrhea, abdominal pain, flatulence, headache, eructation, nausea and rash may be reported in a minority of patients $(47,174,183-186)$. The absorption of fats and minerals does not appear to be significantly impaired, and although serum vitamin $B_{12}$ concentrations may be decreased with prolonged use of high dose PPI therapy (eg, Zollinger-Ellison syndrome) (180), there have been no reports of significant clinical sequelae. Concerns over hypergastrinemia, enterochromaffinlike cell hyperplasia and carcinoid formation have not been substantiated during more than 15 years of widespread PPI use in humans $(88,152)$.

Statement 39*: Prokinetic or promotility agents are not recommended, either alone or in conjunction with antisecretory agents, for the routine long-term treatment of GERD (Level I, A; vote: a $86 \%, b$ 14\%).

Maintenance therapy with cisapride has demonstrated efficacy $(137,187)$ but cisapride is no longer generally available and there are insufficient data to support the use of other prokinetics for maintenance monotherapy. The addition of a prokinetic to PPI maintenance therapy produced no significant added benefit compared with PPI monotherapy (188). There are insufficient published data to make recommendations on the efficacy of other currently available prokinetic agents (128,189-192).

Statement $40^{*}$ : Supplementary nighttime $\mathrm{H}_{2} \mathrm{RA}$ therapy is not generally recommended for individuals who have responded incompletely or have failed to respond to standard dose or double dose PPI therapy of adequate duration (Level I, A; vote: a 77\%, b 23\%).

'Nocturnal acid breakthrough' has been defined as nighttime periods with gastric $\mathrm{pH}$ less than 4.0 lasting for longer than $1 \mathrm{~h}$ during twice-daily PPI therapy (193), but there are no data to show that this is clinically significant or that suppression of nocturnal acid breakthrough is beneficial $(194,195)$. Although the addition of an $\mathrm{H}_{2} \mathrm{RA}$ at bedtime to PPI treatment can reduce gastric nocturnal acid breakthrough (196198), there is no evidence that this improves symptoms or quality of life in GERD patients. An evening dose of omeprazole was more effective than a bedtime dose of ranitidine at controlling intragastric $\mathrm{pH}$ in healthy volunteers (199); furthermore, tolerance to the nocturnal acid suppressing effects of an $\mathrm{H}_{2} \mathrm{RA}$ developed by one week (197). The addition of night time ranitidine in patients with GERD receiving twicedaily omeprazole increased intragastric $\mathrm{pH}$, but there was no significant improvement in reflux events compared with placebo (194).

Statement 41: Surgical antireflux therapy is an alternative to medical therapy for the long-term management of selected patients with GERD (Level I, A; vote a 65\%, b 35\%).

Although surgery is effective, it shows little long-term advantage over medical therapy and may not eliminate the need for medication in many cases. In a randomized trial, antireflux surgery was superior to PPI therapy in terms of symptomatic relapse, but if patients increased the PPI dose at relapse, there was no significant difference between the treatment strategies at three and five years of follow-up $(127,171)$. Furthermore, in this study, the costs for medical therapy were significantly less than those for surgical therapy at five years (200). In an earlier study (201), antireflux surgery was superior to what was then optimal medical therapy $\left(\mathrm{H}_{2} \mathrm{RA}\right.$ with antacids or metoclopramide, as needed) in improving symptoms and esophagitis for up to two years. However, in a long-term follow-up (median 10 years), $92 \%$ of patients in the medical therapy group and $62 \%$ of those in the surgery groups were using antireflux medications regularly (202).

Potential indications for antireflux surgery, for patients with typical GERD manifestations, include regurgitation-dominant or volume-related reflux symptoms (although there is no proven superiority for surgery for this indication), dissatisfaction with a need for long-term PPI therapy (whether at stable or increasing doses), poor compliance (for example, due to medication costs) and the presence of a large hiatus hernia. If patients are considering antireflux surgery, they should be aware of its limitations, including the possibility of relapse necessitating repeat surgery or resumption of medical therapy, and the absence of documented benefit in preventing Barrett's epithelium and esophageal adenocarcinoma. Furthermore, it is important to note that factors predictive of a poor outcome following antireflux surgery include a prior lack of response to PPI therapy $(203,204)$. In large case series, the incidence of serious, fatal or life-threatening complications has been less than $1 \%$ $(205,206)$. Transient (less than two months) postoperative dysphagia occurs in up to $20 \%$ of patients, and longer term dysphagia requiring dilation has been reported in $4 \%$ to $9 \%$ of patients undergoing antireflux surgery $(207,208)$. The group felt that antireflux surgery is appropriate only at centres where the procedure is performed regularly because the outcome is highly dependent on the experience and skill of the surgeon and support services $(209,210)$. The development of minimal access, laparoscopic techniques has led, in many centres, to increased rates of antireflux surgery but both open and laparoscopic techniques continue to be used. A recent structured review and meta-analysis concluded that laparoscopic fundoplication is as effective as open surgery but with lower morbidity rates and more rapid recovery and discharge from hospital (211).

Statement 42: The role of endoscopic antireflux procedures for the management of GERD in clinical practice has not been adequately defined (Level II-3, D [ie, fair evidence that this procedure should not be used]; vote: a 87\%, b 9\%, c 4\%).

Long-term data on the use of endoscopic techniques and devices are not yet available. Most endoscopic techniques are 
intended to increase lower esophageal sphincter pressure or reduce transient lower esophageal sphincter relaxations, thereby decreasing acid reflux. Studies assessing a radiofrequency device (Stretta, Curon Medical, USA), transoral, flexible endoscopic suturing (EndoCinch Suturing System, Bard Endoscopic Technologies, USA), and implantation of polymethylmethacrylate beads (Gatekeeper Reflux Repair System, Medtronic, USA) or a nonabsorbed biocompatible polymer (Enteryx, Boston Scientific, USA) have reported reduced symptoms, medication use and esophageal acid exposure at six to 12 months in some patients with uncomplicated GERD (212-222). However, the improvements in acid exposure were limited, and published trials have only entered patients with mild to moderate GERD; thus, the outcomes of endoscopic therapy cannot be directly compared with those of surgery or standard medical therapy. The Consensus group felt there were currently insufficient published data comparing endoscopic techniques to standard medical or surgical therapy (153) to recommend the routine use of endoscopic antireflux therapy outside the context of a controlled clinical trial.

\section{HELICOBACTER PYLORI INFECTION}

Statement 43*: Testing for Helicobacter pylori infection is not necessary before starting treatment for typical symptoms of GERD (Level I, B; vote: a 82\%, b 9\%, c 9\%).

Statement 44*: The presence of erosive esophagitis at endoscopy does not preclude testing for $\mathrm{H}$ pylori (Level II-2, A; vote: a $64 \%$, b $32 \%$, c $5 \%$ ).

$H$ pylori infection potentiates the acid suppressive effects of PPIs, and patients who are positive for $H$ pylori have a higher intragastric $\mathrm{pH}$ than those who are negative $(223,224)$. Furthermore, there is some evidence that GERD healing and symptom relief rates with PPI therapy are higher in $\mathrm{H}$ pyloripositive than in $H$ pylori-negative patients $(225,226)$. Because there is no evidence that $H$ pylori infection plays a causative role in the pathogenesis of GERD, there is no need for eradication before treating GERD symptoms. This is consistent with published guidelines for the management of uninvestigated dyspepsia, which recommend empiric therapy for typical GERD symptoms before H pylori testing is considered (8).

On the other hand, $H$ pylori is a class I carcinogen (227) and its eradication improves gastritis in $H$ pylori-positive patients with GERD (228). In addition, eradication does not appear to alter the therapeutic dose of omeprazole or cause an increase in reflux symptoms (228). Several studies have also demonstrated that $H$ pylori eradication in patients with refluxlike uninvestigated dyspepsia is associated with a reduction in symptoms including heartburn (229-231). In a one-year follow-up study, $H$ pylori eradication did not seem to influence relapse rates in patients with GERD (232). Although there is considerable controversy in the literature regarding the effect of $H$ pylori eradication on development of GERD (228,232-236), there is no clear consensus that the reported increase in GERD prevalence is causally related to the reduced prevalence of $H$ pylori infection in the western world $(237,238)$. Thus, there appears to be no reason why gastric biopsies should not be taken to test for $\mathrm{H}$ pylori infection if erosive esophagitis is diagnosed at endoscopy.
Statement 45: It is not necessary to test routinely for $\mathrm{H}$ pylori in a patient taking long-term PPI therapy for GERD symptoms (Level II-3, C; vote: a $74 \%, b$ 26\%).

Statement 46: Eradication of $\mathrm{H}$ pylori has no clinically relevant, adverse effect on the long-term outcome of GERD (Level I, A; vote a $87 \%, b 13 \%$ ).

Overall, it appears doubtful that $H$ pylori infection has any effect on the pathogenic mechanisms determining either reflux or its complications (239). Omeprazole therapy in patients who are $\mathrm{H}$ pylori-positive led to an increase in corpus gastritis, which was reversed by eradication of H pylori $(228,240)$; however, in a later study, acid suppressive therapy for three years did not increase gastric glandular atrophy or intestinal metaplasia in H pylori-infected GERD patients (241). H pylori infection causes gastritis, regardless of whether there is concomitant acid suppression therapy; although atrophic gastritis is a risk factor for the development of intestinal metaplasia and gastric cancer, there is no evidence to suggest that PPI therapy is an additional risk factor or that $\mathrm{H}$ pylori eradication affects the risk of gastric cancer in the presence of PPI therapy. Thus, it was not considered necessary to routinely test for $\mathrm{H}$ pylori in GERD patients receiving chronic PPI therapy; however, in accordance with the recommendations of the Canadian $H$ pylori Study Group, patients with a documented $H$ pylori infection should be offered eradication therapy (242) and there is no reason to deny eradication therapy to patients requiring long-term GERD therapy.

\section{BARRETT'S EPITHELIUM}

\section{Definitions}

Statement 47*: The presence and extent of reflux-related columnar metaplasia in the distal esophagus should be recorded in a standardized manner as 'endoscopic suspicion of Barrett's epithelium'; a formal diagnosis of 'Barrett's epithelium' requires histological confirmation (Level III, B; vote: a 64\%, b 36\%).

Statement 48*: Barrett's epithelium is defined as the presence of abnormal epithelium ('endoscopic suspicion of Barrett's epithelium'), of any extent, extending proximally beyond the limit of the gastroesophageal junction, that demonstrates specialized intestinal metaplasia ('esophageal columnar epithelium; intestinal metaplasia positive') on histological examination of the endoscopic biopsies (vote: a 68\%, b 27\%, d 5\%).

This definition of Barrett's epithelium is comparable with that used in many clinical studies; however, there is no general agreement on a formal definition. The American College of Gastroenterology defined Barrett's esophagus as "a change in the esophageal epithelium of any length that can be recognized at endoscopy and is confirmed to have intestinal metaplasia by biopsy of the tubular esophagus and excludes intestinal metaplasia of the cardia" (243). A change extending less than $3 \mathrm{~cm}$ is referred to as short segment Barrett's esophagus while $3 \mathrm{~cm}$ or greater is referred to as long segment Barrett's esophagus. The gastroesophageal junction refers to the most proximal extent of the gastric mucosal folds when the stomach is deflated and the esophagus is minimally distended. The true prevalence of Barrett's epithelium is not known, in part because of differences in the diagnostic criteria for Barrett's esophagus. Population-based studies have reported a prevalence of 23/100,000 to 376/100,000 individuals $(244,245)$ but, 
among symptomatic patients with GERD, the rate of Barrett's epithelium is higher, at an estimated $2 \%$ to $18 \%(29,246,247)$. Among patients in whom Barrett's epithelium was found during endoscopy for GERD symptoms, short segment Barrett's epithelium $(6 \%$ to $10 \%)$ was more common than classical Barrett's epithelium (5\%) (247). In Canadian, predominantly white patients with uninvestigated dyspepsia, Barrett's esophagus was confirmed in $2.4 \%$ of patients overall, including $4.1 \%$ in the group with dominant symptoms of heartburn and $1.4 \%$ in the remaining patients (33).

\section{Risk of esophageal cancer}

Statement 49: Barrett's epithelium is associated with the development of esophageal adenocarcinoma (Level II-3, B; vote: a 96\%, b 4\%).

It is postulated that gastroesophageal reflux leads to metaplasia such that the normal esophageal squamous epithelium changes to a specialized intestinal glandular epithelium in a small proportion of GERD patients, and that this may then progress, by way of dysplasia (low and high grade) to esophageal adenocarcinoma $(248,249)$.

Older studies suggested that the annual risk of adenocarcinoma in Barrett's esophagus was $1 \%$ to $2 \%$, but a recent analysis suggested that this is an overestimate due to publication bias of smaller studies showing higher risks (250). More recent studies suggest that the risk of adenocarcinoma is approximately $0.4 \%$ per person-year of follow-up in patients with Barrett's epithelium (202,251-255) compared with only $0.07 \%$ per year in patients who do not have Barrett's epithelium (202).

Statement 50: The risk of esophageal adenocarcinoma increases with the severity, frequency and duration of GERD symptoms (Level II-2, A; vote: a 95\%, b 0\%, c 0\%, d 5\%).

Patients with a long duration of GERD, especially white males with more severe and frequent reflux symptoms, have a higher risk of esophageal adenocarcinoma (256-261). For example, compared with subjects who had no symptoms, the odds ratios for developing esophageal adenocarcinoma were 7.7 in patients with recurrent reflux symptoms and 43.5 in those with long-standing (greater than 20 years), frequent, severe symptoms (256).

Risk factors for the development of adenocarcinoma in patients with Barrett's epithelium include: white, male, longer duration, severity and frequency of GERD, size of hiatal hernia, obesity, smoking, diet low in fresh fruit, dysplasia (247) and, possibly, the length of esophagus involved by Barrett's epithelium (247). However, many patients with esophageal adenocarcinoma have no identifiable risk factors and no prior diagnosis or symptoms of GERD.

Statement 51*: Neither medical nor surgical therapy has been proven to prevent the development or progression of Barrett's epithelium or the subsequent development of esophageal adenocarcinoma (Level I, D [ie, fair evidence that these strategies should not be used for prevention]; vote: $a 82 \%, b 9 \%, c 5 \%, d 5 \%$ ).

The goals of therapy in patients with Barrett's epithelium include symptom control, maintenance of mucosal healing, regression of Barrett's epithelium, and regression of dysplasia. Management includes acid suppressive medication, ablative therapies or surgery. Four randomized controlled trials have assessed acid suppressive therapy with a PPI, $\mathrm{H}_{2} \mathrm{RA}$ or antireflux surgery in patients with Barrett's epithelium (202,262264). Acid suppression was associated with symptom control but not with disappearance of Barrett's epithelium despite some reports of regression. Antireflux surgery did not prevent progression, with dysplasia developing in $10.5 \%$ and adenocarcinoma in $2.5 \%$ of 161 patients seven to 21 years postoperatively (265). In two long-term studies, there was no difference in the rate of development of esophageal adenocarcinoma between patients receiving medical or surgical antireflux therapy $(202,264)$. No study has demonstrated a reduction in esophageal adenocarcinoma rates with medical or surgical acid suppression (266). The theoretical potential for benefit from surgery with respect to prevention of malignancy may be outweighed by the operative risks (267), while there are no documented risks to long-term medical therapy with a PPI. For the role of endoscopic ablative therapies in treating established Barrett's epithelium, see statement 61.

\section{Screening}

Statement 52: Endoscopic screening for Barrett's esophagus in patients with longstanding GERD has not been shown to reduce mortality from esophageal adenocarcinoma (Level III, C; vote: a 39\%, b 44\%, c 9\%, d 4\%, e 4\%).

Statement 53: Endoscopy to detect Barrett's esophagus with dysplasia may be considered in adults with GERD symptoms for more than 10 years (Level III, C; vote: a 96\%, b 4\%).

Although screening for Barrett's epithelium is controversial, guidelines from the American College of Gastroenterology recommend a 'once in a lifetime' gastroscopy for the detection of Barrett's epithelium in patients with chronic GERD symptoms (243). In a recent survey, this strategy was favoured by $76 \%$ of Canadian gastroenterologists (268), although it should be noted that this is associated with a high cost and unproven benefit. The rationale for screening patients with chronic GERD is that a long duration of GERD, especially in white males with more severe and frequent GERD, confers an increased risk of Barrett's epithelium and adenocarcinoma (256,257). Other risk factors, including nocturnal reflux symptoms, GERD complications (esophagitis, ulceration, bleeding) and hiatus hernia might also influence the need for screening (247). However, it was estimated that the risk of esophageal adenocarcinoma (0.00065/patient/year) would be lower than the risk of endoscopic complications, based on American population data ( 77 million adults over 50 years old in the USA, of whom $14 \%$ or 10 million had weekly GERD symptoms) (269). In addition, because $40 \%$ of patients with esophageal adenocarcinoma do not have weekly reflux symptoms, they would not be identified by a symptom-based surveillance strategy. Although there was support for endoscopy in patients with GERD symptoms for more than 10 years, it was also noted that esophageal adenocarcinoma is very uncommon in patients younger than 50 years of age and therefore, the benefit of a screening endoscopy in such patients remains unproven.

Although many patients with Barrett's epithelium are asymptomatic, general population screening was not recommended. However, patients undergoing endoscopy for any reason should be examined for Barrett's epithelium with confirmatory biopsies if there is endoscopic suspicion of Barrett's epithelium.

The group noted that any screening or surveillance program for Barrett's epithelium would have important implications for health care delivery because of the high cost $(\mathrm{CDN} \$ 300$ for 
endoscopy alone [270] to CDN $\$ 530$ for endoscopy and biopsies [271]) and limited availability of endoscopy in Canada, and the potentially high costs of the programs themselves $(272,273)$. Furthermore, there is no indication for screening and surveillance in patients who are ineligible, a priori, for esophagectomy or ablative therapy because of age or significant comorbidities.

\section{Surveillance}

Statement 54*: Endoscopic surveillance in patients with Barrett's epithelium should include a standard biopsy protocol and should be performed while the patient continues to take therapy sufficient to optimize symptom relief (Level III, C; vote: a 64\%, b 14\%, c $18 \%, d 5 \%)$.

Statement 55: Patients with Barrett's epithelium and dysplasia should generally undergo surveillance (Level III, C; vote: a 83\%, b $17 \%)$.

Statement 56: In the presence of low-grade dysplasia, surveillance endoscopy should be repeated within 12 months with a concentrated biopsy protocol and repeated annually until there is no dysplasia (Level II-3, B; vote: a 65\%, b 35\%).

Statement 57: Patients with Barrett's epithelium in the absence of dysplasia should generally undergo surveillance (Level III, C; vote: a $13 \%, b 48 \%, c 4 \%, d 35 \%)$.

Statement 58: For patients with Barrett's epithelium, in the absence of dysplasia, enrolled in a surveillance program, endoscopy should be repeated every two to five years (Level III, C; vote: a 4\%, b $65 \%, c 4 \%, d 26 \%)$.

Surveillance is recommended in patients with Barrett's epithelium and dysplasia, because dysplasia (graded as absent, indefinite, low- or high-grade) is a risk factor for esophageal adenocarcinoma. The risk of progression to cancer is greater with high-grade than with low-grade dysplasia (274). Unfortunately, there is significant interobserver variability in the grading of dysplasia, with less than $50 \%$ agreement in the classification of low-grade dysplasia (274). The risk of progression from low to high-grade dysplasia or cancer ranges from $10 \%$ to $28 \%$ over five years (274), and estimates of progression from high-grade dysplasia to cancer range from $16 \%$ to $59 \%$ over five to seven years $(249,275,276)$. Endoscopy should be performed while the patient continues to take effective antisecretory therapy to minimize the impact of inflammation and regeneration on the interpretation of biopsy specimens (65).

Surveillance in patients with Barrett's epithelium without dysplasia is more controversial. Barrett's epithelium is the only endoscopically identifiable precursor to esophageal adenocarcinoma, a cancer that is increasing in prevalence in Western societies and has a very poor prognosis if not detected early. There is limited evidence that surveillance programs may lead to earlier cancer detection and improved survival (277-279), and retrospective analyses suggest that patients undergoing surveillance had better two-year ( $86 \%$ versus 43\%) (280) and five-year (62\% versus 20\%) (279) survival rates for esophageal cancer than those who did not undergo surveillance.

However, there are also strong arguments against surveillance. There is a low absolute incidence of esophageal cancer in Canada of 4.06/100,000 (281), and the benefits of surveillance are not clearly defined as they are in colon cancer. Surveillance endoscopy is expensive and time-consuming. About $93 \%$ to $98 \%$ of esophageal adenocarcinomata occur in patients without a prior diagnosis of Barrett's epithelium (247,282). Analysis of patients with esophageal adenocarcinoma in Denmark over a 20-year period found that Barrett's esophagus was diagnosed more than one year before the cancer diagnosis in only $1.3 \%$ of cases (282). Finally, it has been suggested that surveillance may be of marginal benefit because most patients with Barrett's epithelium do not die from esophageal cancer (283). During a nine-year follow-up of 166 patients with Barrett's epithelium, only eight patients developed esophageal cancer, which was the cause of death in only two cases (283).

Recommendations for the frequency of surveillance are based largely on cost-effectiveness modelling studies. Using an estimated cancer rate of $0.4 \%$ per year, Provenzale et al (251) estimated the costs of surveillance every one to five years compared with no surveillance, with esophagectomy performed if high-grade dysplasia was diagnosed. Based on incremental cost-utility ratios, surveillance every five years was the only economically viable strategy in the USA. More frequent surveillance cost more and yielded a lower life expectancy, due to the need for more endoscopies and a greater incidence of complications. The incremental costutility ratio for surveillance every five years was $\$ 98,000 /$ quality-adjusted life year (QALY) gained, which, although less than the estimated cost of $\$ 590,000$ for surveillance every two years, is substantially more than the $\$ 20,000 / \mathrm{QALY}$ to $\$ 22,000 / \mathrm{QALY}$ estimated for colon and breast cancer screening. However, because these ratios may not be relevant to a Canadian practice setting, there is a need for modelling studies using Canadian data.

Surveillance, like screening endoscopy (statements 52 and 53), has significant implications for health care resource utilization. Opinion on the advisability of surveillance was divided (statement 57) because of concerns that it was associated with limited documented benefit in the face of significant costs. On the other hand, there was also concern that failure to undertake surveillance would fall below the standard of care implied by the American College of Gastroenterology guidelines (243). Finally, surveillance was not endorsed for patients who are ineligible for esophagectomy or ablative therapy.

\section{Management}

Statement 59: When high-grade dysplasia is detected for the first time, endoscopy should be repeated within three months with a concentrated biopsy protocol and expert pathologist review of all biopsies (Level II-3, B; vote: a 83\%, b 17\%).

Statement 60: In the presence of confirmed high-grade dysplasia or malignancy, expert consultations should be obtained to ascertain the optimal endoscopic or surgical management strategy (Level III, B; vote: a $87 \%, b 13 \%)$.

In most cases, the presence of high-grade dysplasia should be confirmed by repeat endoscopy and biopsies within three months of initial detection after the patient has had continuous treatment with double dose (twice-daily standard dose) PPI to heal associated erosive esophagitis and minimise refluxrelated injury, inflammation and proliferative changes. However, for some patients, such as those with multifocal high-grade dysplasia, referral for therapy does not require a repeat confirmatory endoscopy (243). 
Endoscopic mucosal resection and ablation are available in some centres for the management of localized, high-grade dysplasia but experience to date is limited $(275,284-290)$. In general, surgery is the recommended strategy for patients who are otherwise healthy but it should be done in centres where these procedures are performed regularly (291). Esophagectomy can be associated with important side effects including dumping syndrome, dysphagia, diarrhea, early satiety and weight loss, and can reduce quality of life substantially (264,292-295). Vagal-sparing esophagectomy and other techniques are under investigation and may be promising in the future. Endoscopic treatments require further study before they can be routinely recommended. Optimal management will generally require input from one or more appropriate specialists in the fields of gastroenterology, oncology, gastrointestinal histopathology and thoracic surgery.

Statement 61*: Ablation therapy should be considered for individuals with high-grade dysplasia or esophageal adenocarcinoma who are unfit for or unwilling to undergo surgery (Level I, A; vote: a 77\%, b $18 \%$, c 5\%).

Patients with coexisting major medical conditions who are not suitable for surgery may benefit from other therapeutic interventions, including photodynamic therapy (PDT), endoscopic mucosal resection, thermal destruction, Nd:YAG (neodymium: yttrium aluminum garnet) laser ablation, injection therapy, esophageal dilation, placement of prosthetic tubes (296), argon plasma coagulation and bipolar electrocoagulation (297). Two randomized controlled trials have assessed ablative PDT in patients with Barrett's epithelium $(284,286,287)$. Ablation of high-grade dysplasia was accomplished in $80 \%$ of patients treated with PDT plus omeprazole compared with $40 \%$ of those treated with omeprazole alone $(284,285)$. At two years of follow-up, there were significantly fewer cases of cancer with PDT compared with omeprazole alone (13\% versus 28\%) (287). However, there is a significant risk of stricture after PDT $(37 \%$ of patients) and the procedure is costly $(284,285)$. The procedure is most promising for patients not suitable for surgery who have high-grade dysplasia or superficial adenocarcinoma. Several case series have reported positive results with endoscopic mucosal resection (288-290).

\section{ECONOMICS}

Burden of illness studies show that GERD is a costly illness, with the highest annual direct costs of all gastrointestinal and liver diseases, at $\$ 9.3$ billion a year in the USA (298). At $\$ 5.89$ billion, drugs constituted the largest component of direct costs. In Canada, over $\$ 670$ million is spent on PPI and $\mathrm{H}_{2} \mathrm{RA}$ therapy annually (299).

PPI therapy is a cost-effective alternative to $\mathrm{H}_{2} \mathrm{RA}$ therapy for the long-term medical management of GERD (300-305). The higher acquisition costs for PPIs versus $\mathrm{H}_{2} \mathrm{RAs}$ are partially offset by gains in health status (304). Treatment with PPIs resolves symptoms more rapidly and prevents symptomatic recurrence more effectively $(300,304)$. Results of decision analysis comparing different empirical treatment strategies with $\mathrm{H}_{2}$ RAs and PPIs demonstrated that initial treatment with PPIs followed by on-demand therapy was a cost-effective approach (301). This strategy produced more QALYs at a lower cost than the $\mathrm{H}_{2} \mathrm{RA}$, step-up, step-down and continuous PPI strategies. The cost-effectiveness ratios were \$20,934/QALY gained for patients with moderate to severe GERD symptoms, and $\$ 37,923$ for patients with mild GERD symptoms versus a reference strategy of lifestyle modification. A Canadian analysis found that PPI maintenance (incremental \$98,000/QALY) and intermittent PPI (incremental \$12,000/QALY) therapy were more expensive but provided a greater number of symptomfree weeks (7.1 and 5.5, respectively) compared with intermittent $\mathrm{H}_{2} \mathrm{RA}$ therapy (reference strategy) (306).

On-demand therapy with a PPI is a cost-effective management strategy both for patients with $\operatorname{ENRD}(301,307)$ and for those with mild-to-moderate GERD, including Los Angeles grades A and B esophagitis (308). A pooled analysis of data from three six-month trials (307) found that $90 \%$ of patients with ENRD could control symptoms effectively with on-demand esomeprazole $20 \mathrm{mg}$ with $16 \%$ to $61 \%$ lower direct medical costs compared with either intermittent (fourweek acute treatment) or continuous omeprazole treatment.

Medical antireflux therapy may be more cost-effective than surgical antireflux therapy over a five-year time frame (200), although this remains controversial (270). In a randomized controlled trial, 298 patients received either continuing treatment with omeprazole or underwent open antireflux surgery (200). At five years of follow-up, the direct medical costs per patient were lower with medical treatment, but the differences between the two strategies decreased over time. As well, the results were highly dependent on the costs of surgery, which varied greatly among countries (200). However, a Canadian modelling study of medical versus surgical costs found that laparoscopic antireflux surgery was a cost-effective alternative for patients with erosive esophagitis compared with long-term PPI maintenance therapy provided that the symptomatic failure rate was less than $10 \%$ per year and that maintenance PPI therapy cost more than $\$ 38.60$ per month (270). While the initial cost of surgery is higher, it becomes the more cost-effective option at 3.3 years of follow-up. The clinical implications of analyses such as these in clinical practice are unclear in part because the outcomes are dependent on the baseline assumptions - especially the country on which the modelling is based, and the costs of surgical and medical therapy. The effectiveness and cost-effectiveness of antireflux surgery for other reasons, including extraesophageal GERD and ENRD, has not been studied.

\section{FUTURE DIRECTIONS}

Although GERD is one of the most common conditions in the Western world, there is a surprising paucity of information on its natural history, sequelae and the effect of long-term management strategies on outcomes. Future research should focus on areas where data are lacking, to provide evidence that will improve the diagnosis, treatment and, potentially, prevention of GERD and its complications. International consensus on the definition and diagnosis of GERD should be a priority. In addition, more data are needed on:

- risk factors for the development of GERD including diet, obesity, medication, $H$ pylori status, genetics and acid secretory status;

- the role of endoscopy in GERD management;

- the long-term prognosis of GERD, on and off treatment;

- the risk of developing Barrett's epithelium and esophageal adenocarcinoma across the spectrum of patients with GERD; 
- the relationship between gastroesophageal reflux and the development of NCCP and extraesophageal disease including asthma, chronic cough, wheezing, hoarseness, ear pain, laryngopharyngitis and dental erosions;

- the outcomes and costs for various evidence-based strategies for the management of GERD in clinical practice.

\section{APPENDIX: LIST OF ATTENDEES}

Nonvoting chairs: John Marshall (JKM), David Armstrong (DA)

Voting participants: Canadian: Mehran Anvari (MA), Bill Bartle (BB), Naoki Chiba (NC), André Duranceau (AD), Robert Enns (RE), Carlo Fallone (CF), Nigel Flook (NF), Krishnasamy Govender (KG), Roger Hollingworth (RH), Richard H. Hunt (RHH), Liisa Jaakkimainen (LJ), Walter Kutcher (WK), Norman Marcon (NM), Serge Mayrand (SM), Anthony Otley (AO), William Paterson (WP), Joseph Romagnuolo (JR), Dan Sadowski (DS), Phil Sherman (PS), Sander van Zanten (SVZ). International: Ronnie Fass (RF), Peter Kahrilas (PK), Paul Moayyedi (PM).

Represented societies: Canadian Association of Gastroenterology (CAG), CAG Practice Affairs Committee, CAG Endoscopy Committee, Canadian Association of General Surgeons, Canadian Association of Primary Care Gastroenterology (CanGut), College of Family Physicians of Canada, CAG Liason Committee, CAG Pediatrics Committee.

Nonvoting observers: Hassen M Abdullah (Therapeutic Products Directorate, Health Canada), Paul Sinclair (CAG), and representatives of the pharmaceutical industry. The meeting was open for observation by nonparticipating physicians.

ACKNOWLEDGEMENTS: The authors wish to thank Pauline Lavigne for the preparation of the manuscript, and Dr AN Barkun for review of the manuscript. We also acknowledge the contribution of Cathy Yuan, Sandra Daniels and Paul Sinclair in assisting in the organization of the Consensus Conference. The CAG would like to thank the sponsors, Abbott Laboratories Ltd, Altana Pharma Canada Inc, AstraZeneca Canada, GlaxoSmithKline Consumer Health Care, Janssen-Ortho Inc, Solvay Pharma Inc, Axcan Pharma Inc, Boston Scientific Ltd, Curon Medical, Medtronic of Canada Ltd, Pentax Precision Instrument Corp, and the Canadian Institutes for Health Research and acknowledge the receipt of unrestricted grants to support the meeting.

Disclosure of potential conflict of interest: No, I do not have any industry or government relationships to report: $(\mathrm{KG}, \mathrm{RH}, \mathrm{LJ}$, WK, AO).

Receipt of consultation fees: Abbott (NC, CF, PS), Allergan (PK), Altana (DA, NC, RE, CF, RF, NF), AstraZeneca (DA, BB, NC, RE, CF, RF, NF, RHH, PK, WP, JR, SVZ), Axcan (RHH), Canadian Medical Protective Association (AD), Enteromedics (MA), Eisai Japan (RF), Eisai USA (RF), GlaxoSmithKline (NF, RHH), Janssen-Ortho (DA, BB, NC, CF, RF, PK, JR, SVZ), Medtronics (PK), Merck Frosst (RHH), Negma (RHH), Nicox (RHH), Novartis (BB, NF, PK, SVZ), Ontario Ministry of Health and Long-term Care (JKM), Pfizer (NF), Solvay (NF), TAP Pharmaceuticals (RF, RHH), Wyeth (RF), Xillix Vancouver (NM).

Receipt of research grants: Abbott (DA, CF, DS); Altana (DA, RE); AstraZeneca (DA, RE, CF, RF, PK, DS, PS, SVZ); Axcan
(JKM); Canadian Association of Gastroenterology Partnership Program (JR); Canadian Institutes of Health Research (MA, JKM, PS); Canadian Health Infrastructure Partnership Program (CHIPP) (MA); Eli Lilly (DS); Given Imaging-Southmedic (RE); JanssenOrtho (RF, RK); Medtronics (RF); Merck Frosst (RHH); Negma (RHH); Novartis (RF); Ontario Ministry of Health and Long-term Care (MA); Proctor \& Gamble (JKM); Shire (RF); Solvay (DA); TAP Pharmaceuticals (RF); Teva (JKM).

Receipt of clinical trial funding: Abbott (RE, CF, JKM, DS, SVZ); Altana (DA, NC, RE, CF, JKM, DS); AstraZeneca (DA, NC, RE, CF, RF, PK, NM, WP, JR, DS, SVZ); Axcan (NC, CF, NM, JKM, SVZ); Ferring (NC); GlaxoSmithKline (CF, RF, WP, SVZ); Janssen-Ortho (CF, PK); Medtronics (PK); Merck Frosst (RHH, NM); Negma (NC, CF, RHH); Novartis (DA, NC, RF, SVZ); Otsuka (RHH); Pfizer (SVZ); Solvay (JKM); TAP Pharmaceuticals (RF); Wyeth (RF).

Participation in speaker's bureau: Abbott (DA, NC, CF, NF, JKM, SM, WP, PS); Allergan (PK); Altana (DA, NC, RE, CF, NF, JKM, SM, WP, JR); AstraZeneca (DA, BB, NC, RE, CF, RF, NF, RHH, PK, SM, NM, PM, WP, JR); Axcan (NC, NM, JR); Boston Scientific (JR); GlaxoSmithKline (NF); Janssen-Ortho (BB, CF, RF, PK, JR); Medtronics (PK); Merck Frosst (RHH, JKM); Negma (RHH); Novartis (BB, CF, RF, NF, RHH, PK, JKM, SVZ); Pfizer (NC, NF); Solvay (NF, JR); Takeda (PM); TAP Pharmaceuticals (RHH); Wyeth (RF, PM).

Significant shareholdings: None reported.

Other: SCI Educational (PS), Ontario Drug Benefit Formulary (DA).

Grant support: This work was supported in part by unrestricted grants to the CAG from Abbott Laboratories Ltd, Altana Pharma Canada Inc, AstraZeneca Canada, GlaxoSmithKline Consumer Health Care, Janssen-Ortho Inc, Solvay Pharma Inc, Axcan Pharma Inc, Boston Scientific Ltd, Curon Medical, Medtronic of Canada Ltd, Pentax Precision Instrument Corp, and the Canadian Institutes for Health Research.

This Consensus Conference was endorsed and organized by the Canadian Association of Gastroenterology and was held in Banff, Alberta, Canada, on March 1-2, 2004.

\section{REFERENCES}

1. Tougas G, Chen Y, Hwang P, Liu M, Eggleston A. Prevalence and impact of upper gastrointestinal symptoms in the Canadian population: Findings from the DIGEST study.

Domestic/International Gastroenterology Surveillance Study. Am J Gastroenterol 1999;94:2845-54.

2. Revicki DA, Sorensen S, Maton PN, Orlando RC. Health-related quality of life outcomes of omeprazole versus ranitidine in poorly responsive symptomatic gastroesophageal reflux disease. Dig Dis 1998;16:284-91.

3. Revicki DA, Crawley JA, Zodet MW, Levine DS, Joelsson BO. Complete resolution of heartburn symptoms and health-related quality of life in patients with gastro-oesophageal reflux disease. Aliment Pharmacol Ther 1999;13:1621-30.

4. Mathias S, Colwell H, Miller D, et al. Health-related quality-of-life and quality-days incrementally gained in symptomatic nonerosive GERD patients treated with lansoprazole or ranitidine. Dig Dis Sci 2001;46:2416-23.

5. Venables TL, Newland RD, Patel AC, Hole J, Wilcock C, Turbitt ML. Omeprazole 10 milligrams once daily, omeprazole 20 milligrams once daily, or ranitidine 150 milligrams twice daily, evaluated as initial therapy for the relief of symptoms of gastro-oesophageal reflux disease in general practice. Scand J Gastroenterol 1997;32:965-73. 
6. Revicki D, Wood M, Maton P, Sorensen S. The impact of gastroesophageal reflux disease on health-related quality of life. Am J Med 1998;104:252-8.

7. Beck IT, Champion MC, Lemire S, et al. The second Canadian consensus conference on the management of patients with gastroesophageal reflux disease. Can J Gastroenterol 1997;11(Suppl B):7B-20B

8. Veldhuyzen van Zanten S, Flook N, Chiba N, et al. An evidencebased approach to the management of uninvestigated dyspepsia in the era of Helicobacter pylori. Canadian Dyspepsia Working Group. CMAJ 2000;162:S3-23.

9. Dent J, Brun J, Fendrick A, et al. An evidence-based appraisal of reflux disease management - the Genval Workshop Report. Gut 1999;44(Suppl 2):S1-16.

10. Armstrong D. Endoscopic evaluation of gastro-esophageal reflux disease. Yale J Biol Med 1999;72:93-100.

11. Armstrong D, Bennett J, Blum A, et al. The endoscopic assessment of esophagitis: A progress report on observer agreement. Gastroenterology 1996;111:85-92.

12. Lundell L, Dent J, Bennett J, et al. Endoscopic assessment of oesophagitis: Clinical and functional correlates and further validation of the Los Angeles classification. Gut 1999;45:172-80.

13. Kahrilas P, Quigley E. Clinical esophageal pH recording: A technical review for practice guideline development. Gastroenterology 1996;110:1982-96.

14. Rudolph C, Mazur L, Liptak G, et al. Guidelines for evaluation and treatment of gastroesophageal reflux in infants and children: Recommendations of the North American Society for Pediatric Gastroenterology and Nutrition. J Pediatr Gastroenterol Nutr 2001;32(Suppl 2):S1-31.

15. Hayward RS, Wilson MC, Tunis SR, et al. More informative abstracts of articles describing clinical practice guidelines. Ann Intern Med 1993;118:731-7.

16. Lomas J. Words without action? The production, dissemination, and impact of consensus recommendations. Annu Rev Public Health 1991;12:41-65.

17. Field MJ, Lohr KN, eds. Clinical Practice Guidelines. Directions For a New Program. Washington, DC: National Academy Press, 1990.

18. Field MJ, Lohr KN, eds. Clinical Practice Guidelines: From Development to Use. Washington, DC: National Academy Press, 1992.

19. Cluzeau FA, Littlejohns P, Grimshaw JM, Feder G, Moran SE. Development and application of a generic methodology to assess the quality of clinical guidelines. Int J Qual Health Care 1999;11:21-8.

20. Eccles M, Clapp Z, Grimshaw J, et al. North of England evidence based guidelines development project: Methods of guideline development. BMJ 1996;312:760-2.

21. Talley N, Venables T, Green J, et al. Esomeprazole $40 \mathrm{mg}$ and $20 \mathrm{mg}$ is efficacious in the long-term management of patients with endoscopy-negative gastro-oesophageal reflux disease: A placebocontrolled trial of on-demand therapy for 6 months. Eur J Gastroenterol Hepatol 2002;14:857-63.

22. Cook DJ, Greengold NL, Ellrodt AG, Weingarten SR. The relation between systematic reviews and practice guidelines. Ann Intern Med 1997;127:210-6.

23. Dalkey N. An experimental study of group opinion: The Delphi Method. Futures 1969:408-26.

24. Canadian Task Force on the Periodic Health Examination. The periodic health examination: 1 . Introduction. CMAJ 1986;134:721-3.

25. Giacomini M, Cook D, Streiner D, Anand S. Using practice guidelines to allocate medical technologies. An ethics framework. Int J Technol Assess Health Care 2000;16:987-1002.

26. Spechler S. Epidemiology and natural history of gastro-oesophageal reflux disease. Digestion 1992;51(Suppl 1):24-9.

27. Wienbeck M, Barnert J. Epidemiology of reflux disease and reflux esophagitis. Scand J Gastroenterol Suppl 1989;156:7-13

28. Akdamar K, Ertan A, Agrawal N, McMahon F, Ryan J. Upper gastrointestinal endoscopy in normal asymptomatic volunteers. Gastrointest Endosc 1986;32:78-80.

29 Shaheen N, Provenzale D. The epidemiology of gastroesophageal reflux disease. Am J Med Sci 2003;326:264-73.

30. Galmiche J, Barthelemy P, Hamelin B. Treating the symptoms of gastro-oesophageal reflux disease: A double-blind comparison of omeprazole and cisapride. Aliment Pharmacol Ther 1997;11:765-73.

31. Carlsson R, Dent J, Watts R, et al. Gastro-oesophageal reflux disease in primary care: An international study of different treatment strategies with omeprazole. International GORD Study Group. Eur J Gastroenterol Hepatol 1998;10:119-24.

32. Lind T, Havelund T, Carlsson R, et al. Heartburn without oesophagitis: Efficacy of omeprazole therapy and features determining therapeutic response. Scand J Gastroenterol 1997;32:974-9.

33. Thomson A, Barkun A, Armstrong D, et al. The prevalence of clinically significant endoscopic findings in primary care patients with uninvestigated dyspepsia: The Canadian Adult Dyspepsia Empiric Treatment - Prompt Endoscopy (CADET-PE) study. Aliment Pharmacol Ther 2003;17:1481-91.
34. Frank L, Kleinman L, Ganoczy D, et al. Upper gastrointestinal symptoms in North America: Prevalence and relationship to healthcare utilization and quality of life. Dig Dis Sci 2000;45:809-18.

35. Henke C, Levin T, Henning J, Potter L. Work loss costs due to peptic ulcer disease and gastroesophageal reflux disease in a health maintenance organization. Am J Gastroenterol 2000;95:788-92

36. Dean B, Crawley J, Schmitt C, Wong J, Ofman J. The burden of illness of gastro-oesophageal reflux disease: Impact on work productivity. Aliment Pharmacol Ther 2003;17:1309-17.

37. Vakil N, Shaker R, Johnson D, et al. The new proton pump inhibitor esomeprazole is effective as a maintenance therapy in GERD patients with healed erosive oesophagitis: A 6-month, randomized, doubleblind, placebo-controlled study of efficacy and safety. Aliment Pharmacol Ther 2001;15:927-35.

38. Johnson D, Benjamin S, Vakil N, et al. Esomeprazole once daily for 6 months is effective therapy for maintaining healed erosive esophagitis and for controlling gastroesophageal reflux disease symptoms: A randomized, double-blind, placebo-controlled study of efficacy and safety. Am J Gastroenterol 2001;96:27-34.

39. van Pinxteren B, Numans M, Lau J, et al. Short-term treatment of gastroesophageal reflux disease. J Gen Intern Med 2003;18:755-63.

40. Fass R. Epidemiology and pathophysiology of symptomatic gastroesophageal reflux disease. Am J Gastroenterol 2003;98:S2-7.

41. Garcia-Compean D, Gonzalez M, Galindo G, et al. Prevalence of gastroesophageal reflux disease in patients with extraesophageal symptoms referred from otolaryngology, allergy, and cardiology practices: A prospective study. Dig Dis 2000;18:178-82.

42. Hewson E, Sinclair J, Dalton C, Richter J. Twenty-four-hour esophageal $\mathrm{pH}$ monitoring: The most useful test for evaluating noncardiac chest pain. Am J Med 1991;90:576-83.

43. Lam H, Dekker W, Kan G, Breedijk M, Smout A. Acute noncardiac chest pain in a coronary care unit. Evaluation by 24-hour pressure and $\mathrm{pH}$ recording of the esophagus. Gastroenterology 1992;102:453-60.

44. Castell D, Kahrilas P, Richter J, et al. Esomeprazole (40 mg) compared with lansoprazole $(30 \mathrm{mg})$ in the treatment of erosive esophagitis. Am J Gastroenterol 2002;97:575-83.

45. Kahrilas P, Falk G, Johnson D, et al. Esomeprazole improves healing and symptom resolution as compared with omeprazole in reflux oesophagitis patients: A randomized controlled trial. The Esomeprazole Study Investigators. Aliment Pharmacol Ther 2000;14:1249-58.

46. Lauritsen K, Deviere J, Bigard M, et al. Esomeprazole $20 \mathrm{mg}$ and lansoprazole $15 \mathrm{mg}$ in maintaining healed reflux oesophagitis: Metropole study results. Aliment Pharmacol Ther 2003;17:333-41.

47. Richter J, Kahrilas P, Johanson J, et al. Efficacy and safety of esomeprazole compared with omeprazole in GERD patients with erosive esophagitis: A randomized controlled trial. Am J Gastroenterol 2001;96:656-65.

48. DeVault K, Castell D, The Practice Parameters Committee of the American Gastroenterological Association. Updated guidelines for the diagnosis and treatment of gastroesophageal reflux disease. Am J Gastroenterol 1999;94:1434-42.

49. Moayyedi P, Duffy J, Delaney B. New approaches to enhance the accuracy of the diagnosis of reflux disease. Gut 2004:53(Suppl 4):iv55-7.

50. Clouse R, Richter J, Heading R, Janssens J, Wilson J. Functional esophageal disorders. Gut 1999;45(Suppl 2):II31-6.

51. Fass R, Tougas G. Functional heartburn: The stimulus, the pain, and the brain. Gut 2002;51:885-92

52. Moayyedi P, Forman D, Braunholtz D, et al. The proportion of upper gastrointestinal symptoms in the community associated with Helicobacter pylori, lifestyle factors, and nonsteroidal antiinflammatory drugs. Leeds HELP Study Group. Am J Gastroenterol 2000;95:1448-55

53. Klauser A, Schindlbeck N, Muller-Lissner S. Symptoms in gastrooesophageal reflux disease. Lancet 1990;335:205-8.

54. Carlsson R, Dent J, Bolling-Sternevald E, et al. The usefulness of a structured questionnaire in the assessment of symptomatic gastroesophageal reflux disease. Scand J Gastroenterol 1998;33:1023-9.

55. Fass R, Ofman J, Gralnek I, et al. Clinical and economic assessment of the omeprazole test in patients with symptoms suggestive of gastroesophageal reflux disease. Arch Intern Med 1999;159:2161-8.

56. Schenk B, Kuipers E, Klinkenberg-Knol E, et al. Omeprazole as a diagnostic tool in gastroesophageal reflux disease. Am J Gastroenterol 1997;92:1997-2000.

57. Fass R, Ofman J, Sampliner R, et al. The omeprazole test is as sensitive as 24 -h oesophageal $\mathrm{pH}$ monitoring in diagnosing gastrooesophageal reflux disease in symptomatic patients with erosive oesophagitis. Aliment Pharmacol Ther 2000;14:389-96.

58. Armstrong D, Veldhuyzen van Zanten S, Barkun A, et al. Symptom 
improvement at one week to predict outcome at four weeks with esomeprazole (E) in uninvestigated dyspepsia (UD) patients: The confirmatory acid suppression test (CAST) study. Can J Gastroenterol 2004;18(Supp A):130A. (Abst)

59. Fass R, Fennerty M, Ofman J, et al. The clinical and economic value of a short course of omeprazole in patients with noncardiac chest pain. Gastroenterology 1998;115:42-9.

60. Bautista J, Fullerton H, Briseno M, Cui H, Fass R. The effect of an empirical trial of high-dose lansoprazole on symptom response of patients with non-cardiac chest pain - a randomized, double-blind, placebo-controlled, crossover trial. Aliment Pharmacol Ther 2004;19:1123-30.

61. Ofman J, Gralnek I, Udani J, Fennerty M, Fass R. The costeffectiveness of the omeprazole test in patients with noncardiac chest pain. Am J Med 1999;107:219-27.

62. Spechler S. American Gastroenterological Association medical position statement on treatment of patients with dysphagia caused by benign disorders of the distal esophagus. Gastroenterology $1999 ; 117: 229-33$

63. Dakkak M, Bennett J. A new dysphagia score with objective validation. J Clin Gastroenterol 1992;14:99-100.

64. Richter J. Severe reflux esophagitis. Gastrointest Endosc Clin N Am 1994;4:677-98.

65. Armstrong D. Motion - All patients with GERD should be offered once in a lifetime endoscopy: Arguments for the motion. Can J Gastroenterol 2002;16:549-51.

66. Thjodleifsson B, Beker JA, Dekkers C, et al. Rabeprazole versus omeprazole in preventing relapse of erosive or ulcerative gastroesophageal reflux disease: A double-blind, multicenter, European trial. The European Rabeprazole Study Group. Dig Dis Sci 2000;45:845-53.

67. Nayar D, Vaezi M. Classifications of esophagitis: Who needs them? Gastrointest Endosc 2004;60:253-7.

68. Richter J. Diagnostic tests for gastroesophageal reflux disease. Am J Med Sci 2003;326:300-8

69. Stolte M, Vieth M, Schmitz JM, Alexandridis T, Seifert E. Effects of long-term treatment with proton pump inhibitors in gastrooesophageal reflux disease on the histological findings in the lower oesophagus. Scand J Gastroenterol 2000;35:1125-30.

70. Armstrong D, Vieth M, Fiocca R, et al. Are endoscopy negative GERD and reflux esophagitis different diseases? Baseline histology in GERD patients off-therapy - the CHEER Study. Gastroenterology 2003;124:A416. (Abst)

71. Ismail-Beigi F, Horton P, Pope C. Histological consequences of gastroesophageal reflux in man. Gastroenterology 1970;58:163-74.

72. Tobey N, Carson J, Alkiek R, Orlando R. Dilated intercellular spaces: A morphological feature of acid reflux - damaged human esophageal epithelium. Gastroenterology 1996;111:1200-5.

73. Armstrong D, Vieth M, Deprez P, et al. Esomeprazole therapy and esophageal histology in endoscopy negative reflux disease (ENRD) the CHEER Study. Gastroenterology 2003;124:A416. (Abst)

74. Solcia E, Villani L, Luinetti O, et al. Altered intercellular glycoconjugates and dilated intercellular spaces of esophageal epithelium in reflux disease. Virchows Arch 2000;436:207-16.

75. Martinez S, Malagon I, Garewal H, Cui H, Fass R. Non-erosive reflux disease (NERD) - acid reflux and symptom patterns. Aliment Pharmacol Ther 2003; 17:537-45

76. Johnston B, Troshinsky M, Castell J, Castell D. Comparison of barium radiology with esophageal $\mathrm{pH}$ monitoring in the diagnosis of gastroesophageal reflux disease. Am J Gastroenterol 1996;91:1181-5.

77. Poynard T, Vernisse B, Agostini H. Randomized, multicentre comparison of sodium alginate and cisapride in the symptomatic treatment of uncomplicated gastro-oesophageal reflux. Aliment Pharmacol Ther 1998;12:159-65.

78. Kitchin L, Castell D. Rationale and efficacy of conservative therapy for gastroesophageal reflux disease. Arch Intern Med $1991 ; 151: 448-54$.

79. Chiba N, De Gara CJ, Wilkinson JM, Hunt RH. Speed of healing and symptom relief in grade II to IV gastroesophageal reflux disease A meta-analysis. Gastroenterology 1997;112:1798-810.

80. Hunt R. Importance of $\mathrm{pH}$ control in the management of GERD. Arch Intern Med 1999;159:649-57.

81. Johansson K, Ask P, Boeryd B, Fransson S, Tibbling L. Oesophagitis, signs of reflux, and gastric acid secretion in patients with symptoms of gastro-oesophageal reflux disease. Scand J Gastroenterol 1986;21:837-47.

82. Pujol A, Grande L, Ros E, Pera C. Utility of inpatient 24-hour intraesophageal $\mathrm{pH}$ monitoring in diagnosis of gastroesophageal reflux. Dig Dis Sci 1988;33:1134-40.

83. Masclee A, de Best A, de Graaf R, Cluysenaer O, Jansen J. Ambulatory 24-hour pH-metry in the diagnosis of gastroesophageal reflux disease. Determination of criteria and relation to endoscopy. Scand J Gastroenterol 1990;25:225-30.

84. Kasapidis P, Xynos E, Mantides A, et al. Differences in manometry and 24-H ambulatory $\mathrm{pH}$-metry between patients with and without endoscopic or histological esophagitis in gastroesophageal reflux disease. Am J Gastroenterol 1993;88:1893-9.

85. Saraswat V, Dhiman R, Mishra A, Naik S. Correlation of 24-hr esophageal $\mathrm{pH}$ patterns with clinical features and endoscopy in gastroesophageal reflux disease. Dig Dis Sci 1994;39:199-205.

86. Hunt R. The relationship between the control of $\mathrm{pH}$ and healing and symptom relief in gastro-oesophageal reflux disease. Aliment Pharmacol Ther 1995;9 Suppl 1:3-7.

87. Orlando R. Why is the high grade inhibition of gastric acid secretion afforded by proton pump inhibitors often required for healing of reflux esophagitis? An epithelial perspective. Am J Gastroenterol 1996;91:1692-6.

88. Bell N, Hunt R. Progress with proton pump inhibition. Yale J Biol Med 1992;65:649-57.

89. Caro JJ, Salas M, Ward A. Healing and relapse rates in gastroesophageal reflux disease treated with the newer proton-pump inhibitors lansoprazole, rabeprazole, and pantoprazole compared with omeprazole, ranitidine, and placebo: Evidence from randomized clinical trials. Clin Ther 2001;23:998-1017.

90. Armstrong D. 'Start high' - a better acid suppression strategy for heartburn-dominant uninvestigated dyspepsia (UD) in primary care practice (PCP) - the CADET-HR study. Can J Gastroenterol 2002;16(Suppl A):144A. (Abst)

91. Festen H, Schenk E, Tan G, Snel P, Nelis F. Omeprazole versus highdose ranitidine in mild gastroesophageal reflux disease: Short- and long-term treatment. The Dutch Reflux Study Group. Am J Gastroenterol 1999;94:931-6.

92. Jansen J, Van OJ. Standard-dose lansoprazole is more effective than high-dose ranitidine in achieving endoscopic healing and symptom relief in patients with moderately severe reflux oesophagitis. The Dutch Lansoprazole Study Group. Aliment Pharmacol Ther 1999;13:1611-20.

93. Kahrilas P, Fennerty M, Joelsson B. High-versus standard-dose ranitidine for control of heartburn in poorly responsive acid reflux disease: a prospective, controlled trial. Am J Gastroenterol 1999;94:92-7.

94. Ehrlich A, Lucker P, Wiedemann A, et al. Comparison of the pharmacodynamics and pharmacokinetics of pantoprazole $(40 \mathrm{mg})$ as compared to omeprazole MUPS (20 mg) after repeated oral dose administration. Methods Find Exp Clin Pharmacol 1999;21:47-51.

95. Galmiche J, Zerbib F, Ducrotte P, et al. Decreasing oesophageal acid exposure in patients with GERD: A comparison of rabeprazole and omeprazole. Aliment Pharmacol Ther 2001;15:1343-50.

96. Dammann H, Burkhardt F. Pantoprazole versus omeprazole: Influence on meal-stimulated gastric acid secretion. Eur J Gastroenterol Hepatol 1999; 11:1277-82.

97. Katz P, Hatlebakk J, Castell D. Gastric acidity and acid breakthrough with twice-daily omeprazole or lansoprazole. Aliment Pharmacol Ther 2000;14:709-14.

98. Katz P, Xue S, Castell D. Control of intragastric $\mathrm{pH}$ with omeprazole $20 \mathrm{mg}$, omeprazole $40 \mathrm{mg}$ and lansoprazole $30 \mathrm{mg}$. Aliment Pharmacol Ther 2001;15:647-52.

99. Pantoflickova D, Dorta G, Ravic M, Jornod P, Blum A. Acid inhibition on the first day of dosing: Comparison of four proton pump inhibitors. Aliment Pharmacol Ther 2003;17:1507-14.

100. Frazzoni M, De ME, Grisendi A, Savarino V. Effective intraoesophageal acid suppression in patients with gastro-oesophageal reflux disease: Lansoprazole vs. pantoprazole. Aliment Pharmacol Ther 2003; 17:235-41.

101. Huang J, Goldwater D, Thomson A, et al. Acid suppression in healthy subjects following lansoprazole or pantoprazole. Aliment Pharmacol Ther 2002;16:425-33

102. Wilder-Smith C, Rohss K, Nilsson-Pieschl C, Junghard O, Nyman L. Esomeprazole $40 \mathrm{mg}$ provides improved intragastric acid control as compared with lansoprazole $30 \mathrm{mg}$ and rabeprazole $20 \mathrm{mg}$ in healthy volunteers. Digestion 2003;68:184-8.

103. Miner P, Katz P, Chen Y, Sostek M. Gastric acid control with esomeprazole, lansoprazole, omeprazole, pantoprazole, and rabeprazole: A five-way crossover study. Am J Gastroenterol 2003;98:2616-20.

104. Lind T, Rydberg L, Kyleback A, et al. Esomeprazole provides improved acid control vs. omeprazole in patients with symptoms of gastro-oesophageal reflux disease. Aliment Pharmacol Ther 2000;14:861-7.

105. Rohss K, Hasselgren G, Hedenstrom H. Effect of esomeprazole $40 \mathrm{mg}$ vs omeprazole $40 \mathrm{mg}$ on 24-hour intragastric $\mathrm{pH}$ in patients with symptoms of gastroesophageal reflux disease. Dig Dis Sci 2002;47:954-8.

106. Wilder-Smith C, Bondarov P, Hallerbäck B, et al. Esomeprazole $40 \mathrm{mg}$ intravenous provides faster and more effective acid control than pantoprazole $40 \mathrm{mg}$ intravenous after first dose and 5 days. Gut 2003;52(Suppl VI):A129. (Abst)

107. Simon B, Muller P, Pascu O, et al. Intra-oesophageal pH profiles and pharmacokinetics of pantoprazole and esomeprazole: 
A crossover study in patients with gastro-oesophageal reflux disease. Eur J Gastroenterol Hepatol 2003;15:791-9.

108. Wilder-Smith C, Lind T, Lundin C, et al. Comparison of esomeprazole 20, 40, $80 \mathrm{mg}$ versus lansoprazole $15,30,60 \mathrm{mg}$ on intragastric $\mathrm{Ph}$ in healthy subjects. Gut 2003;52(Suppl VI):A124. (Abst)

109. Schindlbeck N, Klauser A, Voderholzer W, Muller-Lissner S. Empiric therapy for gastroesophageal reflux disease. Arch Intern Med 1995; 155:1808-12.

110. Klok R, Postma M, van Hout B, Brouwers J. Meta-analysis: Comparing the efficacy of proton pump inhibitors in short-term use. Aliment Pharmacol Ther 2003;17:1237-45.

111. Labenz J, Keeling P, Eklund S, Naucler E, on behalf of the Expo Study Group. A comparison of esomeprazole $40 \mathrm{mg}$ once-daily and pantoprazole $40 \mathrm{mg}$ once-daily for the healing of erosive esophagitis. Can J Gastroenterol 2004;18(Suppl A):118A. (Abst)

112. Gillessen A, Beil W, Modlin I, Gatz G, Hole U. 40 mg pantoprazole and $40 \mathrm{mg}$ esomeprazole are equivalent in the healing of esophageal lesions and relief from gastroesophageal reflux disease-related symptoms. J Clin Gastroenterol 2004;38:332-40.

113. Tack J, Fass R. Review article: Approaches to endoscopic-negative reflux disease: Part of the GERD spectrum or a unique acid-related disorder? Aliment Pharmacol Ther 2004;19(Suppl 1):28-34

114. Miner P, Orr W, Filippone J, Jokubaitis L, Sloan S. Rabeprazole in nonerosive gastroesophageal reflux disease: A randomized placebocontrolled trial. Am J Gastroenterol 2002;97:1332-9.

115. Armstrong D, Talley N, Lauritsen K, et al. The role of acid suppression in patients with endoscopy-negative reflux disease: The effect of treatment with esomeprazole or omeprazole. Aliment Pharmacol Ther 2004;20:413-21.

116. Howden C, Henning J, Huang B, Lukasik N, Freston J. Management of heartburn in a large, randomized, community-based study: Comparison of four therapeutic strategies. Am J Gastroenterol 2001;96:1704-10.

117. van Rensburg C, Honiball P, Grundling H, et al. Efficacy and tolerability of pantoprazole $40 \mathrm{mg}$ versus $80 \mathrm{mg}$ in patients with reflux oesophagitis. Aliment Pharmacol Ther 1996;10:397-401.

118. Fass R, Murthy U, Hayden C, et al. Omeprazole $40 \mathrm{mg}$ once a day is equally effective as lansoprazole $30 \mathrm{mg}$ twice a day in symptom control of patients with gastro-oesophageal reflux disease (GERD) who are resistant to conventional-dose lansoprazole therapy a prospective, randomized, multi-centre study. Aliment Pharmacol Ther 2000;14:1595-603.

119. Hetzel D, Dent J, Reed W, et al. Healing and relapse of severe peptic esophagitis after treatment with omeprazole. Gastroenterology 1988;95:903-12.

120. Richter J, Peura D, Benjamin S, Joelsson B, Whipple J. Efficacy of omeprazole for the treatment of symptomatic acid reflux disease without esophagitis. Arch Intern Med 2000;160:1810-6.

121. Richter J, Bochenek W. Oral pantoprazole for erosive esophagitis: A placebo-controlled, randomized clinical trial. Pantoprazole US GERD Study Group. Am J Gastroenterol 2000;95:3071-80.

122. Castell D, Richter J, Robinson M, Sontag S, Haber M. Efficacy and safety of lansoprazole in the treatment of erosive reflux esophagitis. The Lansoprazole Group. Am J Gastroenterol 1996;91:1749-57.

123. Frazzoni M, De ME, Grisendi A, Savarino V. Lansoprazole vs. omeprazole for gastro-oesophageal reflux disease: $\mathrm{A} \mathrm{pH}$-metric comparison. Aliment Pharmacol Ther 2002;16:35-9.

124. Hatlebakk J, Katz P, Kuo B, Castell D. Nocturnal gastric acidity and acid breakthrough on different regimens of omeprazole $40 \mathrm{mg}$ daily. Aliment Pharmacol Ther 1998;12:1235-40.

125. Hatlebakk J, Katz P, Camacho-Lobato L, Castell D. Proton pump inhibitors: Better acid suppression when taken before a meal than without a meal. Aliment Pharmacol Ther 2000;14:1267-72.

126. Kuo B, Castell D. Optimal dosing of omeprazole $40 \mathrm{mg}$ daily: Effects on gastric and esophageal $\mathrm{pH}$ and serum gastrin in healthy controls. Am J Gastroenterol 1996;91:1532-8.

127. Lundell L, Miettinen P, Myrvold H, et al. Long-term management of gastro-oesophageal reflux disease with omeprazole or open antireflux surgery: Results of a prospective, randomized clinical trial. The Nordic GORD Study Group. Eur J Gastroenterol Hepatol 2000;12:879-87.

128. Armstrong D. The clinical usefulness of prokinetic agents in gastrooesophageal reflux disease. In: Lundell L, ed. Guidelines for Management of Symptomatic Gastro-oesophageal Reflux Disease. London: Science Press, 1998:45-54.

129. Augood C, MacLennan S, Gilbert R, Logan S. Cisapride treatment for gastro-oesophageal reflux in children (Cochrane Review). The Cochrane Library. Chichester, United Kingdom: John Wiley \& Sons Ltd, 2004.

130. van Pinxteren B, Numans M, Bonis P, Lau J. Short-term treatment with proton pump inhibitors, $\mathrm{H}_{2}$-receptor antagonists and prokinetics for gastro-oesophageal reflux disease-like symptoms and endoscopy negative reflux disease. (Cochrane Review). The Cochrane Library. Chichester, United Kingdom: John Wiley \& Sons Ltd, 2004.

131. Bines J, Quinlan J, Treves S, Kleinman R, Winter H. Efficacy of domperidone in infants and children with gastroesophageal reflux. J Pediatr Gastroenterol Nutr 1992;14:400-5.

132. Maddern G, Kiroff G, Leppard P, Jamieson G. Domperidone, metoclopramide, and placebo. All give symptomatic improvement in gastroesophageal reflux. J Clin Gastroenterol 1986;8:135-40.

133. Carroccio A, Iacono G, Montalto G, et al. Domperidone plus magnesium hydroxide and aluminum hydroxide: A valid therapy in children with gastroesophageal reflux. A double-blind randomized study versus placebo. Scand J Gastroenterol 1994;29:300-4.

134. McCallum R, Fink S, Winnan G, Avella J, Callachan C. Metoclopramide in gastroesophageal reflux disease: Rationale for its use and results of a double-blind trial. Am J Gastroenterol 1984;79:165-72.

135. Guslandi M, Testoni P, Passaretti S, et al. Ranitidine vs metoclopramide in the medical treatment of reflux esophagitis. Hepatogastroenterology 1983;30:96-8.

136. Orr W, Finn A, Wilson T, Russell J. Esophageal acid contact time and heartburn in acute treatment with ranitidine and metoclopramide. Am J Gastroenterol 1990;85:697-700.

137. Kimmig J. Treatment and prevention of relapse of mild oesophagitis with omeprazole and cisapride: Comparison of two strategies. Aliment Pharmacol Ther 1995;9:281-6.

138. van Rensburg C, Bardhan K. No clinical benefit of adding cisapride to pantoprazole for treatment of gastro-oesophageal reflux disease. Eur J Gastroenterol Hepatol 2001;13:909-14.

139. Masci E, Testoni P, Passaretti S, Guslandi M, Tittobello A. Comparison of ranitidine, domperidone maleate and ranitidine + domperidone maleate in the short-term treatment of reflux oesophagitis. Drugs Exp Clin Res 1985;11:687-92.

140. Richter J, Sabesin S, Kogut D, et al. Omeprazole versus ranitidine or ranitidine/metoclopramide in poorly responsive symptomatic gastroesophageal reflux disease. Am J Gastroenterol 1996;91:1766-72.

141. Bloom BS, Hillman AL, LaMont B, Liss C, Schwartz JS, Stever GJ Omeprazole or ranitidine plus metoclopramide for patients with severe erosive oesophagitis. A cost-effectiveness analysis. Pharmacoeconomics 1995;8:343-9.

142. Robinson M, Decktor D, Maton P, et al. Omeprazole is superior to ranitidine plus metoclopramide in the short-term treatment of erosive oesophagitis. Aliment Pharmacol Ther 1993;7:67-73.

143. Arabehety J, Leitao O, Fassler S, Olarte M, Serrano C. Cisapride and metoclopramide in the treatment of gastroesophageal reflux disease. Clin Ther 1988;10:421-8.

144. Lieberman D, Keeffe E. Treatment of severe reflux esophagitis with cimetidine and metoclopramide. Ann Intern Med 1986;104:21-6.

145. Shiau J, Shukla V, Dubé C. The efficacy of proton pump inhibitors in adults with functional dyspepsia. Ottawa: Canadian Coordinating Office for Health Technology Assessment, 2002; Technology report no. 22 .

146. Lind T, Havelund T, Lundell L, et al. On demand therapy with omeprazole for the long-term management of patients with heartburn without oesophagitis - a placebo-controlled randomized trial. Aliment Pharmacol Ther 1999;13:907-14.

147. Wilhelmsen I, Hatlebakk JG, Olafsson S, Berstad A. On demand therapy of reflux oesophagitis - a prospective study of symptoms, patient satisfaction and quality of life. Aliment Pharmacol Ther 1999;13:1035-40.

148. Talley N, Lauritsen K, Tunturi-Hihnala H, et al. Esomeprazole $20 \mathrm{mg}$ maintains symptom control in endoscopy-negative gastro-oesophageal reflux disease: a controlled trial of 'on-demand' therapy for 6 months. Aliment Pharmacol Ther 2001;15:347-54.

149. Dent J, Talley N. Overview: Initial and long-term management of gastro-oesophageal reflux disease. Aliment Pharmacol Ther 2003;17(Suppl 1):53-7.

150. Sontag S, Robinson M, Roufail W, et al. Daily omeprazole surpasse intermittent dosing in preventing relapse of oesophagitis: A US multi-centre double-blind study. Aliment Pharmacol Ther 1997;11:373-80.

151. Bytzer P. Goals of therapy and guidelines for treatment success in symptomatic gastroesophageal reflux disease patients. Am J Gastroenterol 2003;98:S31-9.

152. Pohle T, Domschke W. Results of short-and long-term medical treatment of gastroesophageal reflux disease (GERD). Langenbecks Arch Surg 2000;385:317-23.

153. Freston J, Triadafilopoulos G. Approaches to the long-term management of adults with GERD-proton pump inhibitor therapy, laparoscopic fundoplication or endoscopic therapy? Aliment Pharmacol Ther 2004;19(Suppl 1):35-42.

154. Richter J. Long-term management of gastroesophageal reflux disease and its complications. Am J Gastroenterol 1997;92:30S-4S; discussion 4S-5S.

155. Barbezat G, Schlup M, Lubcke R. Omeprazole therapy decreases the 
need for dilatation of peptic oesophageal strictures. Aliment Pharmacol Ther 1999; 13:1041-5.

156. Stal J, Gregor J, Preiksaitis H, Reynolds R. A cost-utility analysis comparing omeprazole with ranitidine in the maintenance therapy of peptic esophageal stricture. Can J Gastroenterol 1998; $12: 43-9$

157. Smith P, Kerr G, Cockel R, et al. A comparison of omeprazole and ranitidine in the prevention of recurrence of benign esophageal stricture. Restore Investigator Group. Gastroenterology 1994;107:1312-8

158. Marks R, Richter J, Rizzo J, et al. Omeprazole versus $\mathrm{H}_{2}$-receptor antagonists in treating patients with peptic stricture and esophagitis. Gastroenterology 1994;106:907-15.

159. Swarbrick E, Gough A, Foster C, et al. Prevention of recurrence of oesophageal stricture, a comparison of lansoprazole and high-dose ranitidine. Eur J Gastroenterol Hepatol 1996;8:431-8.

160. Carlsson R, Galmiche J, Dent J, Lundell L, Frison L. Prognostic factors influencing relapse of oesophagitis during maintenance therapy with antisecretory drugs: A meta-analysis of long-term omeprazole trials. Aliment Pharmacol Ther 1997;11:473-82.

161. Laursen L, Havelund T, Bondesen S, et al. Omeprazole in the longterm treatment of gastro-oesophageal reflux disease. A double-blind randomized dose-finding study. Scand J Gastroenterol 1995;30:839-46.

162. Plein K, Hotz J, Wurzer H, et al. Pantoprazole $20 \mathrm{mg}$ is an effective maintenance therapy for patients with gastro-oesophageal reflux disease. Eur J Gastroenterol Hepatol 2000;12:425-32.

163. Escourrou J, Deprez P, Saggioro A, et al. Maintenance therapy with pantoprazole $20 \mathrm{mg}$ prevents relapse of reflux oesophagitis. Aliment Pharmacol Ther 1999; 13:1481-91.

164. Chiba N. Proton pump inhibitors in acute healing and maintenance of erosive or worse esophagitis: A systematic overview. Can J Gastroenterol 1997;11(Suppl B):66B-73B

165. Robinson M, Lanza F, Avner D, Haber M. Effective maintenance treatment of reflux esophagitis with low-dose lansoprazole. A randomized, double-blind, placebo-controlled trial. Ann Intern Med 1996; $124: 859-67$.

166. Sontag S, Kogut D, Fleischmann R, et al. Lansoprazole prevents recurrence of erosive reflux esophagitis previously resistant to $\mathrm{H}_{2}$-RA therapy. The Lansoprazole Maintenance Study Group. Am J Gastroenterol 1996;91:1758-65.

167. Baldi F, Morselli-Labate A, Cappiello R, Ghersi S. Daily low-dose versus alternate day full-dose lansoprazole in the maintenance treatment of reflux esophagitis. Am J Gastroenterol 2002;97:1357-64

168. Caos A, Moskovitz M, Dayal Y, et al. Rabeprazole for the prevention of pathologic and symptomatic relapse of erosive or ulcerative gastroesophageal reflux disease. Rebeprazole Study Group. Am J Gastroenterol 2000;95:3081-8.

169. Metz D, Bochenek W. Pantoprazole maintenance therapy prevents relapse of erosive oesophagitis. Aliment Pharmacol Ther 2003;17:155-64.

170. Hatlebakk J, Berstad A. Lansoprazole 15 and $30 \mathrm{mg}$ daily in maintaining healing and symptom relief in patients with reflux oesophagitis. Aliment Pharmacol Ther 1997;11:365-72.

171. Lundell L, Miettinen P, Myrvold HE, et al. Continued (5-year) followup of a randomized clinical study comparing antireflux surgery and omeprazole in gastroesophageal reflux disease. J Am Coll Surg 2001;192:172-9; discussion 9-81.

172. Klinkenberg Knol EC, Nelis F, Dent J, et al. Long-term omeprazole treatment in resistant gastroesophageal reflux disease: Efficacy, safety, and influence on gastric mucosa. Gastroenterology 2000;118:661-9.

173. Lamberts R, Brunner G, Solcia E. Effects of very long (up to 10 years) proton pump blockade on human gastric mucosa. Digestion 2001;64:205-13.

174. Maton P, Vakil N, Levine J, et al. Safety and efficacy of long term esomeprazole therapy in patients with healed erosive oesophagitis. Drug Saf 2001;24:625-35.

175. Freston J, Jackson R, Huang B, Ballard E. Lansoprazole for maintenance of remission of erosive oesophagitis. Drugs 2002;62:1173-84

176. Freston J, Rose P, Heller C, Haber M, Jennings D. Safety profile of Lansoprazole: The US clinical trial experience. Drug Saf 1999;20:195-205

177. Bardhan K, Cherian P, Bishop A, et al. Pantoprazole therapy in the long-term management of severe acid peptic disease: Clinical efficacy, safety, serum gastrin, gastric histology, and endocrine cell studies. Am J Gastroenterol 2001;96:1767-76.

178. Van Rensburg CJ, Honiball PJ, Van Zyl JH, et al. Safety and efficacy of pantoprazole $40 \mathrm{mg}$ daily as relapse prophylaxis in patients with healed reflux oesophagitis-a 2-year follow-up. Aliment Pharmacol Ther 1999;13:1023-8.

179. Thjodleifsson B, Rindi G, Fiocca R, et al. A randomized, double-blind trial of the efficacy and safety of 10 or $20 \mathrm{mg}$ rabeprazole compared with $20 \mathrm{mg}$ omeprazole in the maintenance of gastro-oesophageal reflux disease over 5 years. Aliment Pharmacol Ther 2003; 17:343-51.

180. Laine L, Ahnen D, McClain C, Solcia E, Walsh J. Review article: Potential gastrointestinal effects of long-term acid suppression with proton pump inhibitors. Aliment Pharmacol Ther 2000;14:651-68.

181. Cheer S, Prakash A, Faulds D, Lamb H. Pantoprazole: An update of its pharmacological properties and therapeutic use in the management of acid-related disorders. Drugs 2003;63:101-33.

182. Flockhart D, Desta Z, Mahal S. Selection of drugs to treat gastrooesophageal reflux disease: The role of drug interactions. Clin Pharmacokinet 2000;39:295-309.

183. Martin R, Dunn N, Freemantle S, Shakir S. The rates of common adverse events reported during treatment with proton pump inhibitors used in general practice in England: Cohort studies. Br J Clin Pharmacol 2000;50:366-72.

184. Avner D. Clinical experience with pantoprazole in gastroesophageal reflux disease. Clin Ther 2000;22:1169-85; discussion 49-50.

185. Bardhan K, Van Rensburg C. Comparable clinical efficacy and tolerability of $20 \mathrm{mg}$ pantoprazole and $20 \mathrm{mg}$ omeprazole in patients with grade I reflux oesophagitis. Aliment Pharmacol Ther 2001;15:1585-91.

186. Richter J, Campbell D, Kahrilas P, Huang B, Fludas C. Lansoprazole compared with ranitidine for the treatment of nonerosive gastroesophageal reflux disease. Arch Intern Med 2000;160:1803-9.

187. Tytgat G, Blum A, Verlinden M. Prognostic factors for relapse and maintenance treatment with cisapride in gastro-oesophageal reflux disease. Aliment Pharmacol Ther 1995;9:271-80.

188. Vigneri S, Termini R, Leandro G, et al. A comparison of five maintenance therapies for reflux esophagitis. N Engl J Med 1995;333:1106-10

189. Kahrilas P, Quigley E, Castell D, Spechler S. The effects of tegaserod (HTF 919) on oesophageal acid exposure in gastro-oesophageal reflux disease. Aliment Pharmacol Ther 2000;14:1503-9.

190. Cange L, Johnsson E, Rydholm H, et al. Baclofen-mediated gastrooesophageal acid reflux control in patients with established reflux disease. Aliment Pharmacol Ther 2002;16:869-73.

191. Koek G, Sifrim D, Lerut T, Janssens J, Tack J. Effect of the GABA(B) agonist baclofen in patients with symptoms and duodeno-gastrooesophageal reflux refractory to proton pump inhibitors. Gut 2003;52:1397-402.

192. Ciccaglione A, Marzio L. Effect of acute and chronic administration of the GABA B agonist baclofen on 24 hour $\mathrm{pH}$ metry and symptoms in control subjects and in patients with gastro-oesophageal reflux disease. Gut 2003;52:464-70.

193. Peghini P, Katz P, Bracy N, Castell D. Nocturnal recovery of gastric acid secretion with twice-daily dosing of proton pump inhibitors. Am J Gastroenterol 1998;93:763-7.

194. Orr W, Harnish M. The efficacy of omeprazole twice daily with supplemental H2 blockade at bedtime in the suppression of nocturnal oesophageal and gastric acidity. Aliment Pharmacol Ther 2003;17:1553-8.

195. Ours T, Fackler W, Richter J, Vaezi M. Nocturnal acid breakthrough: clinical significance and correlation with esophageal acid exposure. Am J Gastroenterol 2003;98:545-50.

196. Peghini P, Katz P, Castell D. Ranitidine controls nocturnal gastric acid breakthrough on omeprazole: a controlled study in normal subjects. Gastroenterology 1998;115:1335-9.

197. Fackler W, Ours T, Vaezi M, Richter J. Long-term effect of $\mathrm{H}_{2} \mathrm{RA}$ therapy on nocturnal gastric acid breakthrough. Gastroenterology 2002;122:625-32

198. Xue S, Katz P, Banerjee P, Tutuian R, Castell D. Bedtime $\mathrm{H}_{2}$ blockers improve nocturnal gastric acid control in GERD patients on proton pump inhibitors. Aliment Pharmacol Ther 2001;15:1351-6.

199. Khoury R, Katz P, Hammod R, Castell D. Bedtime ranitidine does not eliminate the need for a second daily dose of omeprazole to suppress nocturnal gastric $\mathrm{pH}$. Aliment Pharmacol Ther 1999;13:675-8.

200. Myrvold H, Lundell L, Miettinen P, et al. The cost of long term therapy for gastro-oesophageal reflux disease: A randomised trial comparing omeprazole and open antireflux surgery. Gut 2001;49:488-94.

201. Spechler S. Comparison of medical and surgical therapy for complicated gastroesophageal reflux disease in veterans. The Department of Veterans Affairs Gastroesophageal Reflux Disease Study Group. N Engl J Med 1992;326:786-92.

202. Spechler S, Lee E, Ahnen D, et al. Long-term outcome of medical and surgical therapies for gastroesophageal reflux disease: Follow-up of a randomized controlled trial. JAMA 2001;285:2331-8.

203. Campos G, Peters J, De Meester T, et al. Multivariate analysis of factors predicting outcome after laparoscopic Nissen fundoplication. J Gastrointest Surg 1999;3:292-300.

204. Power C, Maguire D, McAnena O. Factors contributing to failure of laparoscopic Nissen fundoplication and the predictive value of preoperative assessment. Am J Surg 2004;187:457-63. 
205. Finlayson S, Laycock W, Birkmeyer J. National trends in utilization and outcomes of antireflux surgery. Surg Endosc 2003;17:864-7.

206. Rantanen T, Salo J, Sipponen J. Fatal and life-threatening complications in antireflux surgery: analysis of 5,502 operations. Br J Surg 1999;86:1573-7.

207. Leggett PL, Bissell CD, Churchman Winn R, Ahn C. A comparison of laparoscopic Nissen fundoplication and Rossetti's modification in 239 patients. Surg Endosc 2000;14:473-7.

208. Heikkinen TJ, Haukipuro K, Bringman S, et al. Comparison of laparoscopic and open Nissen fundoplication 2 years after operation. A prospective randomized trial. Surg Endosc 2000;14:1019-23.

209. Carlson M, Frantzides C. Complications and results of primary minimally invasive antireflux procedures: A review of 10,735 reported cases. J Am Coll Surg 2001;193:428-39.

210. Flum D, Koepsell T, Heagerty P, Pellegrini C. The nationwide frequency of major adverse outcomes in antireflux surgery and the role of surgeon experience, 1992-1997. J Am Coll Surg 2002;195:611-8.

211. Catarci M, Gentileschi P, Papi C, et al. Evidence-based appraisal of antireflux fundoplication. Ann Surg 2004:239:325-37.

212. Triadafilopoulos G, Di Baise J, Nostrant T, et al. The Stretta procedure for the treatment of GERD: 6 and 12 month follow-up of the U.S. open label trial. Gastrointest Endosc 2002;55:149-56.

213. Filipi C, Lehman G, Rothstein R, et al. Transoral, flexible endoscopic suturing for treatment of GERD: A multicenter trial. Gastrointest Endosc 2001;53:416-22.

214. Feretis C, Benakis P, Dimopoulos C, et al. Endoscopic implantation of Plexiglas (PMMA) microspheres for the treatment of GERD. Gastrointest Endosc 2001;53:423-6.

215. Johnson D, Ganz R, Aisenberg J, et al. Endoscopic implantation of enteryx for treatment of GERD: 12-month results of a prospective, multicenter trial. Am J Gastroenterol 2003;98:1921-30.

216. Corley D, Katz P, Wo J, et al. Improvement of gastroesophageal reflux symptoms after radiofrequency energy: A randomized, shamcontrolled trial. Gastroenterology 2003;125:668-76.

217. Di Baise J, Brand R, Quigley E. Endoluminal delivery of radiofrequency energy to the gastroesophageal junction in uncomplicated GERD: Efficacy and potential mechanism of action. Am J Gastroenterol 2002;97:833-42.

218. Triadafilopoulos G, Dibaise J, Nostrant T, et al. Radiofrequency energy delivery to the gastroesophageal junction for the treatment of GERD. Gastrointest Endosc 2001;53:407-15.

219. Wolfsen H, Richards W. The Stretta procedure for the treatment of GERD: A registry of 558 patients. J Laparoendosc Adv Surg Tech A 2002;12:395-402.

220. Houston H, Khaitan L, Holzman M, Richards W. First year experience of patients undergoing the Stretta procedure. Surg Endosc 2003;17:401-4.

221. Mahmood Z, McMahon B, Arfin Q, et al. Endocinch therapy for gastro-oesophageal reflux disease: A one year prospective follow up Gut 2003;52:34-9.

222. Johnson D, Ganz R, Aisenberg J, et al. Endoscopic, deep mural implantation of Enteryx for the treatment of GERD: 6-month followup of a multicenter trial. Am J Gastroenterol 2003;98:250-8.

223. Verdu E, Armstrong D, Idstrom J, et al. Effect of curing Helicobacter pylori infection on intragastric $\mathrm{pH}$ during treatment with omeprazole. Gut 1995;37:743-8

224. Kuipers E, Klinkenberg-Knol E, Meuwissen S. Helicobacter pylori, proton pump inhibitors and gastroesophageal reflux disease. Yale J Biol Med 1999; 72:211-8.

225. Holtmann G, Cain C, Malfertheiner P. Gastric Helicobacter pylori infection accelerates healing of reflux esophagitis during treatment with the proton pump inhibitor pantoprazole. Gastroenterology 1999;117:11-6

226. Armstrong D, Paré P, Pericak D, Pyzyk M. Symptom relief in gastroesophageal reflux disease: A randomized, controlled comparison of pantoprazole and nizatidine in a mixed patient population with erosive esophagitis or endoscopy-negative reflux disease. Am J Gastroenterol 2001;96:2849-57.

227. Uemura N, Okamoto S, Yamamoto S, et al. Helicobacter pylori infection and the development of gastric cancer. N Engl J Med 2001;345:784-9.

228. Kuipers E, Nelis G, Klinkenberg-Knol E, et al. Cure of Helicobacter pylori infection in patients with reflux oesophagitis treated with long term omeprazole reverses gastritis without exacerbation of reflux disease: Results of a randomised controlled trial. Gut 2004;53:12-20.

229. Chiba N, Veldhuyzen van Zanten S, Sinclair P, et al. Treating Helicobacter pylori infection in primary care patients with uninvestigated dyspepsia: The Canadian adult dyspepsia empiric treatment-Helicobacter pylori positive (CADET-Hp) randomised controlled trial. BMJ 2002;324:1012-6.

230. Moayyedi P, Feltbower R, Brown J, et al. Effect of population screening and treatment for Helicobacter pylori on dyspepsia and quality of life in the community: A randomised controlled trial. Leeds HELP Study Group. Lancet 2000;355:1665-9.
231. Wildner-Christensen M, Moller Hansen J, Schaffalitzky De Muckadell O. Rates of dyspepsia one year after Helicobacter pylori screening and eradication in a Danish population. Gastroenterology 2003;125:372-9.

232. Moayyedi P, Bardhan C, Young L, et al. Helicobacter pylori eradication does not exacerbate reflux symptoms in gastroesophageal reflux disease. Gastroenterology 2001;121:1120-6.

233. Fallone C, Barkun A, Friedman G, et al. Is Helicobacter pylori eradication associated with gastroesophageal reflux disease? Am J Gastroenterol 2000;95:914-20

234. Labenz J. Does Helicobacter pylori affect the management of gastroesophageal reflux disease? Am J Gastroenterol 1999;94:867-9.

235. Labenz J, Malfertheiner P. Helicobacter pylori in gastro-oesophageal reflux disease: causal agent, independent or protective factor? Gut 1997;41:277-80.

236. Fallone CA, Barkun AN, Gottke MU, et al. Association of Helicobacter pylori genotype with gastroesophageal reflux disease and other upper gastrointestinal diseases. Am J Gastroenterol 2000;95:659-69.

237. Holtmann G. Reflux disease: The disorder of the third millennium. Eur J Gastroenterol Hepatol 2001;13(Suppl 1):S5-11.

238. Sharma P. Helicobacter pylori: A debated factor in gastroesophageal reflux disease. Dig Dis 2001;19:127-33

239. Porro G, Pace F. Should we eradicate Helicobacter pylori in patients with recurrent gastro-oesophageal reflux disease? Eur J Gastroenterol Hepatol 2000;12(Suppl 1):S7-10.

240. Kuipers E, Uyterlinde A, Pena A, et al. Increase of Helicobacter pyloriassociated corpus gastritis during acid suppressive therapy: Implications for long-term safety. Am J Gastroenterol 1995;90:1401-6.

241. Lundell L, Miettinen P, Myrvold H, et al. Lack of effect of acid suppression therapy on gastric atrophy. Nordic GERD Study Group. Gastroenterology 1999;117:319-26.

242. Hunt R, Fallone C, Thomson A. Canadian Helicobacter pylori Consensus Conference update: infections in adults. Canadian Helicobacter Study Group. Can J Gastroenterol 1999;13:213-7.

243. Sampliner R. Updated guidelines for the diagnosis, surveillance, and therapy of Barrett's esophagus. Am J Gastroenterol 2002;97:1888-95.

244. Cameron A, Zinsmeister A, Ballard D, Carney J. Prevalence of columnar-lined (Barrett's) esophagus. Comparison of population-based clinical and autopsy findings. Gastroenterology 1990;99:918-22.

245. Conio M, Cameron A, Romero Y, et al. Secular trends in the epidemiology and outcome of Barrett's oesophagus in Olmsted County, Minnesota. Gut 2001;48:304-9.

246. Csendes A, Smok G, Burdiles P, et al. Prevalence of Barrett's esophagus by endoscopy and histologic studies: A prospective evaluation of 306 control subjects and 376 patients with symptoms of gastroesophageal reflux. Dis Esophagus 2000;13:5-11.

247. Fallone C, Bradette M, Chiba N. Barrett's esophagus. In: MacDonald J, ed. Evidence-Based Gastroenterology. London: BMA House, 2004. (In press)

248. Mueller J, Werner M, Siewert J. Malignant progression in Barrett's esophagus: Pathology and molecular biology. Recent Results Cancer Res 2000;155:29-41.

249. Reid B, Levine D, Longton G, Blount P, Rabinovitch P. Predictors of progression to cancer in Barrett's esophagus: Baseline histology and flow cytometry identify low- and high-risk patient subsets. Am J Gastroenterol 2000;95:1669-76.

250. Shaheen N, Crosby M, Bozymski E, Sandler R. Is there publication bias in the reporting of cancer risk in Barrett's esophagus? Gastroenterology 2000;119:333-8.

251. Provenzale D, Schmitt C, Wong J. Barrett's esophagus: A new look at surveillance based on emerging estimates of cancer risk. Am J Gastroenterol 1999;94:2043-53.

252. Rana P, Johnston D. Incidence of adenocarcinoma and mortality in patients with Barrett's oesophagus diagnosed between 1976 and 1986: Implications for endoscopic surveillance. Dis Esophagus 2000;13:28-31.

253. O'Connor J, Falk G, Richter J. The incidence of adenocarcinoma and dysplasia in Barrett's esophagus: Report on the Cleveland Clinic Barrett's Esophagus Registry. Am J Gastroenterol 1999;94:2037-42.

254. Drewitz D, Sampliner R, Garewal H. The incidence of adenocarcinoma in Barrett's esophagus: A prospective study of 170 patients followed 4.8 years. Am J Gastroenterol 1997;92:212-5

255. Conio M, Blanchi S, Lapertosa G, et al. Long-term endoscopic surveillance of patients with Barrett's esophagus. Incidence of dysplasia and adenocarcinoma: a prospective study. Am J Gastroenterol 2003;98:1931-9.

256. Lagergren J, Bergstrom R, Lindgren A, Nyren O. Symptomatic gastroesophageal reflux as a risk factor for esophageal adenocarcinoma. N Engl J Med 1999;340:825-31.

257. Lieberman D, Oehlke M, Helfand M. Risk factors for Barrett's esophagus in community-based practice. GORGE consortium. Gastroenterology Outcomes Research Group in Endoscopy. Am J Gastroenterol 1997;92:1293-7. 
258. Velanovich V, Hollingsworth J, Suresh P, Ben-Menachem T. Relationship of gastroesophageal reflux disease with adenocarcinoma of the distal esophagus and cardia. Dig Surg 2002;19:349-53.

259. Green J, Amaro R, Barkin J. Symptomatic gastroesophageal reflux as a risk factor for esophageal adenocarcinoma. Dig Dis Sci 2000;45:2367-8.

260. Avidan B, Sonnenberg A, Schnell T, et al. Hiatal hernia size, Barrett's length, and severity of acid reflux are all risk factors for esophageal adenocarcinoma. Am J Gastroenterol 2002;97:1930-6.

261. Farrow D, Vaughan T, Sweeney C, et al. Gastroesophageal reflux disease, use of $\mathrm{H}_{2}$ receptor antagonists, and risk of esophageal and gastric cancer. Cancer Causes Control 2000;11:231-8.

262. Peters F, Ganesh S, Kuipers E, et al. Endoscopic regression of Barrett's oesophagus during omeprazole treatment: A randomised double blind study. Gut 1999;45:489-94

263. Ortiz A, Martinez de Haro L, Parrilla P, et al. Conservative treatment versus antireflux surgery in Barrett's oesophagus: Long-term results of a prospective study. Br J Surg 1996;83:274-8

264. Parrilla P, Martinez de Haro L, Ortiz A, et al. Long-term results of a randomized prospective study comparing medical and surgical treatment of Barrett's esophagus. Ann Surg 2003;237:291-8.

265. Csendes A, Burdiles P, Braghetto I, et al. Dysplasia and adenocarcinoma after classic antireflux surgery in patients with Barrett's esophagus: The need for long-term subjective and objective follow-up. Ann Surg 2002;235:178-85

266. Corey K, Schmitz S, Shaheen N. Does a surgical antireflux procedure decrease the incidence of esophageal adenocarcinoma in Barrett's esophagus? A meta-analysis. Am J Gastroenterol 2003;98:2390-4

267. Spechler S. Barrett's esophagus: An overrated cancer risk factor. Gastroenterology 2000;119:587-9.

268. MacNeil-Covin L, Casson A, Malatjalian D, Veldhuyzen van Zanten S. A survey of Canadian gastroenterologists about the management of Barrett's esophagus. Can J Gastroenterol 2003;17:313-7.

269. Shaheen N, Ransohoff D. Gastroesophageal reflux, barrett esophagus, and esophageal cancer: Scientific review. JAMA 2002;287:1972-81.

270. Romagnuolo J, Meier M, Sadowski D. Medical or surgical therapy for erosive reflux esophagitis: Cost-utility analysis using a Markov model. Ann Surg 2002;236:191-202.

271. Marshall J, Armstrong D, O'Brien B. Test and treat strategies for Helicobacter pylori in uninvestigated dyspepsia: A Canadian economic analysis. Can J Gastroenterol 2000;14:379-88.

272. Spechler S, Barr H. Screening and surveillance of Barrett's oesophagus: What is a cost-effective framework? Aliment Pharmacol Ther 2004;19(Suppl 1):49-53.

273. Inadomi J, Sampliner R, Lagergren J, et al. Screening and surveillance for Barrett esophagus in high-risk groups: A cost-utility analysis. Ann Intern Med 2003;138:176-86.

274. Spechler SJ. Clinical practice. Barrett's esophagus. N Engl J Med 2002:346:836-42

275. Schnell T, Sontag S, Chejfec G, et al. Long-term nonsurgical management of Barrett's esophagus with high-grade dysplasia. Gastroenterology 2001;120:1607-19.

276. Buttar N, Wang K, Sebo T, et al. Extent of high-grade dysplasia in Barrett's esophagus correlates with risk of adenocarcinoma. Gastroenterology 2001;120:1630-9.

277. Peters J, Clark G, Ireland A, et al. Outcome of adenocarcinoma arising in Barrett's esophagus in endoscopically surveyed and nonsurveyed patients. J Thorac Cardiovasc Surg 1994;108:813-21; discussion 21-2

278. Corley D, Levin T, Habel L, Weiss N, Buffler P. Surveillance and survival in Barrett's adenocarcinomas: A population-based study. Gastroenterology 2002;122:633-40

279. Streitz J, Andrews C, Ellis F. Endoscopic surveillance of Barrett's esophagus. Does it help? J Thorac Cardiovasc Surg 1993;105:383-7; discussion 7-8.

280. van Sandick J, van Lanschot J, Kuiken B, et al. Impact of endoscopic biopsy surveillance of Barrett's oesophagus on pathological stage and clinical outcome of Barrett's carcinoma. Gut 1998;43:216-22.

281. Cancer Surveillance Online. Cancer incidence by province/territory. Cancer of the esophagus, both sexes combined, all ages. Health Canada, $2000<$ http://dsol-smed.hc-sc.gc.ca/dsol-smed/cgibin/cancerchart2?CAUSE $1=031 \& S E X 1=3 \&$ YEAR $1=$ O0\&DATA TYPE $=$ R\&AGE $1=0 \&$ CPROV $1=$ View + Chart $>($ Version current at December 15, 2004)

282. Bytzer P, Christensen P, Damkier P, Vinding K, Seersholm N. Adenocarcinoma of the esophagus and Barrett's esophagus: A population-based study. Am J Gastroenterol 1999;94:86-91

283. van der Burgh A, Dees J, Hop W, van Blankenstein M. Oesophageal cancer is an uncommon cause of death in patients with Barrett's oesophagus. Gut 1996;39:5-8.

284. Overholt B, Haggitt R, Bronner M, et al. A multicenter, partially blinded randomized study of the efficacy of photodynamic therapy (PDT) using porfimer sodium (POR) for the ablation of high grade dysplasia (HGD) in Barrett's esophagus (BE): Results of a 6 month follow up. Gastroenterology 2001;120:A79.

285. Overholt B, Panjehpour M, Halberg D. Photodynamic therapy for Barrett's esophagus with dysplasia and/or early stage carcinoma: Long term results. Gastrointest Endosc 2003;58:183-8

286. Ackroyd R, Brown N, Davis M, et al. Photodynamic therapy for dysplastic Barrett's oesophagus: A prospective, double blind, randomised, placebo controlled trial. Gut 2000;47:612-7.

287. Overholt B, Lightdale C, Wang K, et al. International, multicenter, partially blinded, randomized study of the efficacy of photodynamic therapy (PDT) using porfimer sodium (POR) for the ablation of high-grade dysplasia (HGD) in Barrett's esophagus (BE): Results of 24-month follow-up. Gastroenterology 2003;124:A20. (Abst)

288. Moreira L, Kamikawa Y, Naomoto Y, Haisa M, Orita K. Endoscopic mucosal resection for superficial carcinoma and high-grade dysplasia of the esophagus. Surg Laparosc Endosc 1995;5:171-5.

289. Ahmad N, Kochman M, Long W, Furth E, Ginsberg G. Efficacy, safety, and clinical outcomes of endoscopic mucosal resection A study of 101 cases. Gastrointest Endosc 2002;55:390-6.

290. Nijhawan P, Wang K. Endoscopic mucosal resection for lesions with endoscopic features suggestive of malignancy and high-grade dysplasia within Barrett's esophagus. Gastrointest Endosc 2000;52:328-32.

291. Lundell L. Surgical therapies in Barrett's esophagus. Gastrointest Endosc Clin N Am 2003;13:433-47, vi.

292. DeMeester TR. Surgical treatment of dysplasia and adenocarcinoma. Gastroenterol Clin North Am 1997;26:669-84.

293. Csendes A. Surgical treatment of Barrett's esophagus: 1980-2003. World J Surg 2004:28:225-31.

294. O'Riordan JM, Byrne PJ, Ravi N, Keeling PW, Reynolds JV. Longterm clinical and pathologic response of Barrett's esophagus after antireflux surgery. Am J Surg 2004;188:27-33.

295. Ruol A, Zaninotto G, Costantini M, et al. Barrett's esophagus: Management of high-grade dysplasia and cancer. J Surg Res 2004;117:44-51.

296. Marcon N. Photodynamic therapy and cancer of the esophagus. Semin Oncol 1994;21:20-3.

297. van den Boogert J, van Hillegersberg R, Siersema P, de Bruin R, Tilanus H. Endoscopic ablation therapy for Barrett's esophagus with high-grade dysplasia: A review. Am J Gastroenterol 1999:94:1153-60

298. Sandler R, Everhart J, Donowitz M, et al. The burden of selected digestive diseases in the United States. Gastroenterology 2002;122:1500-11.

299. IMS Health. Academic Reference Manual. Pointe-Claire, Quebec: IMS, 2002.

300. Kaplan-Machlis B, Spiegler G, Zodet M, Revicki D. Effectiveness and costs of omeprazole vs ranitidine for treatment of symptomatic gastroesophageal reflux disease in primary care clinics in West Virginia. Arch Fam Med 2000;9:624-30.

301. Gerson LB, Robbins AS, Garber A, Hornberger J, Triadafilopoulos G. A cost-effectiveness analysis of prescribing strategies in the management of gastroesophageal reflux disease. Am J Gastroentero 2000;95:395-407.

302. Harris RA, Kuppermann M, Richter JE. Proton pump inhibitors or histamine-2 receptor antagonists for the prevention of recurrences of erosive reflux esophagitis: A cost-effectiveness analysis. Am J Gastroenterol 1997;92:2179-87.

303. Goeree R, O'Brien B, Hunt R, et al. Economic evaluation of longterm management strategies for erosive oesophagitis. Pharmacoeconomics 1999;16:679-97.

304. Ofman J, Yamashita B, Siddique R, Larson L, Willian M. Cost effectiveness of rabeprazole versus generic ranitidine for symptom resolution in patients with erosive esophagitis. Am J Manag Care 2000;6:905-16

305. O'Brien B, Goeree R, Hunt R, et al. Cost-effectiveness of alternative therapies for the long-term management of gastroesophageal reflux disease. Ottawa: Canadian Coordinating Office for Health Technology Assessment (CCOHTA), 1996

306. Goeree R, O'Brien B, Blackhouse G, et al. Cost-effectiveness and cost-utility of long-term management strategies for heartburn. Value Health 2002;5:312-28.

307. Wahlqvist P, Junghard O, Higgins A, Green J. Cost effectiveness of proton pump inhibitors in gastro-oesophageal reflux disease without oesophagitis: Comparison of on-demand esomeprazole with conventional omeprazole strategies. Pharmacoeconomics 2002;20:267-77

308. Wahlqvist P, Junghard O, Higgins A, Green J. Cost effectiveness of esomeprazole compared with omeprazole in the acute treatment of patients with reflux oesophagitis in the UK. Pharmacoeconomics 2002;20:279-87. 


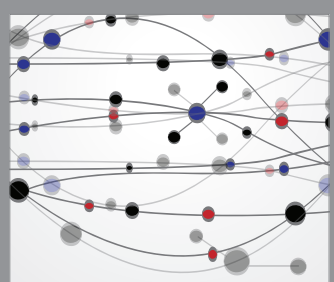

The Scientific World Journal
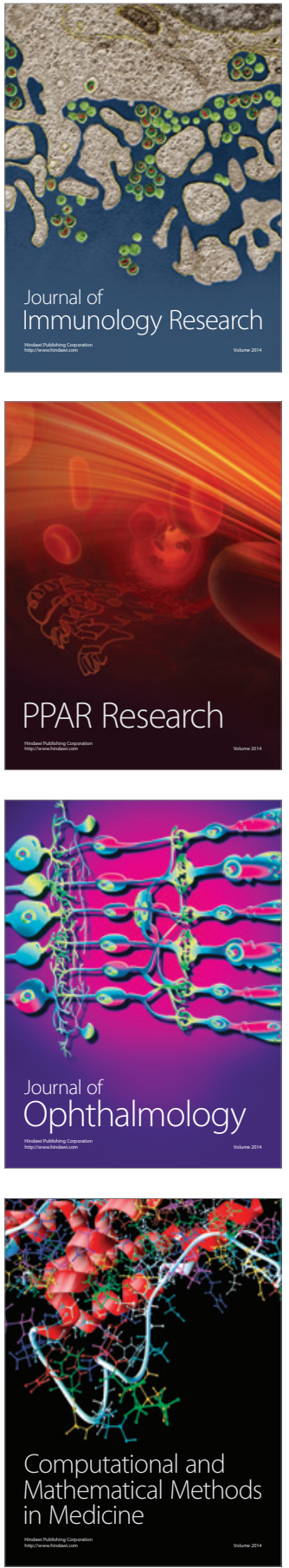

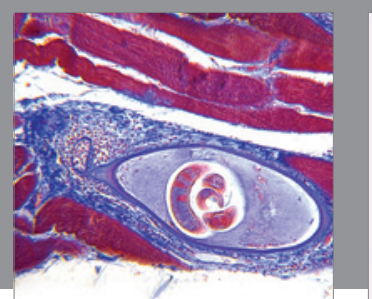

Gastroenterology Research and Practice

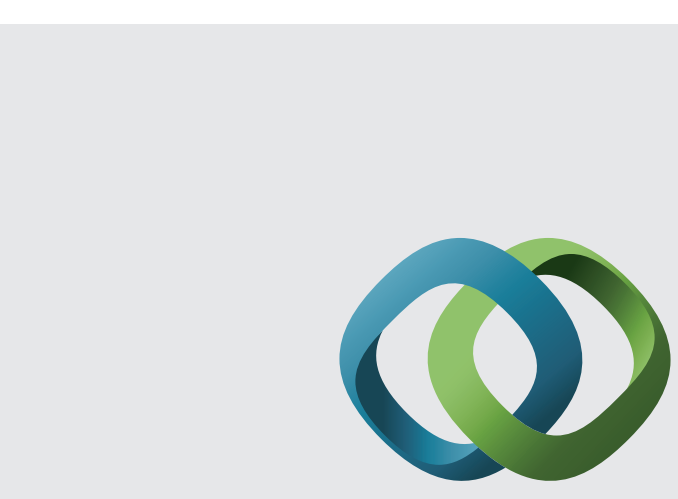

\section{Hindawi}

Submit your manuscripts at

http://www.hindawi.com
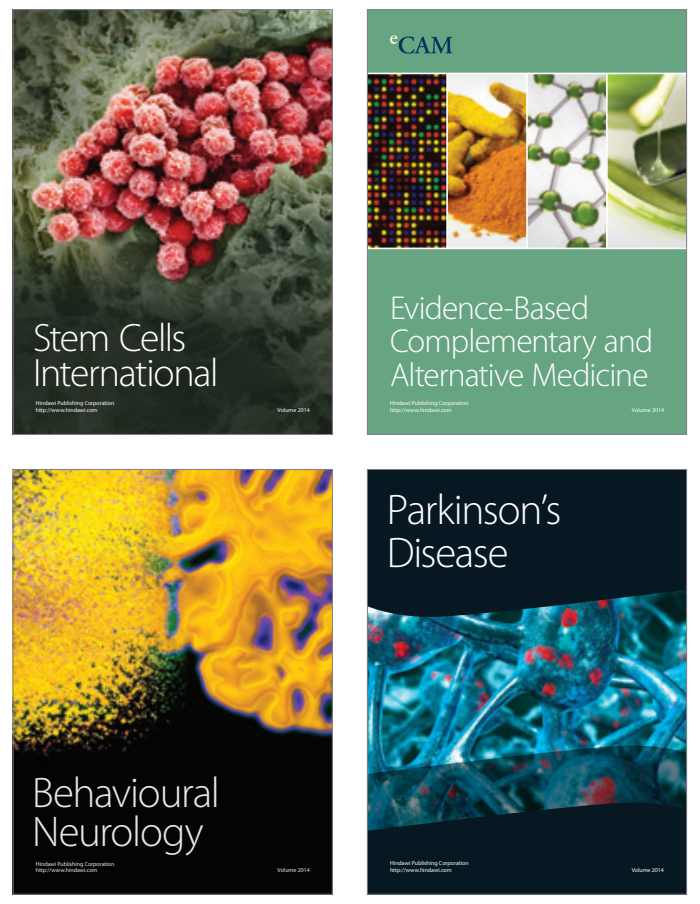
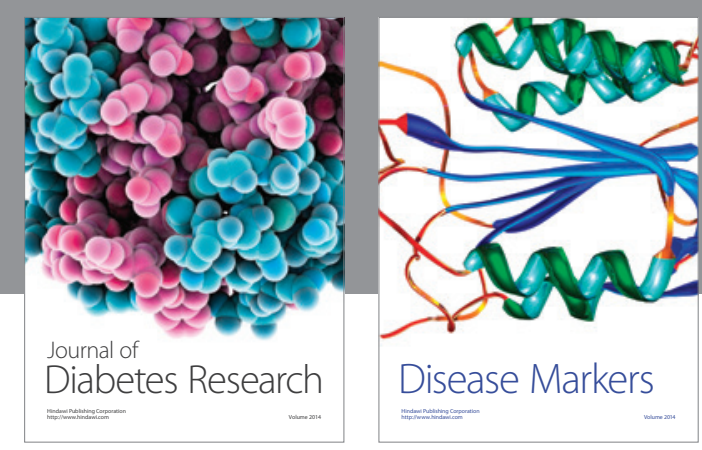

Disease Markers
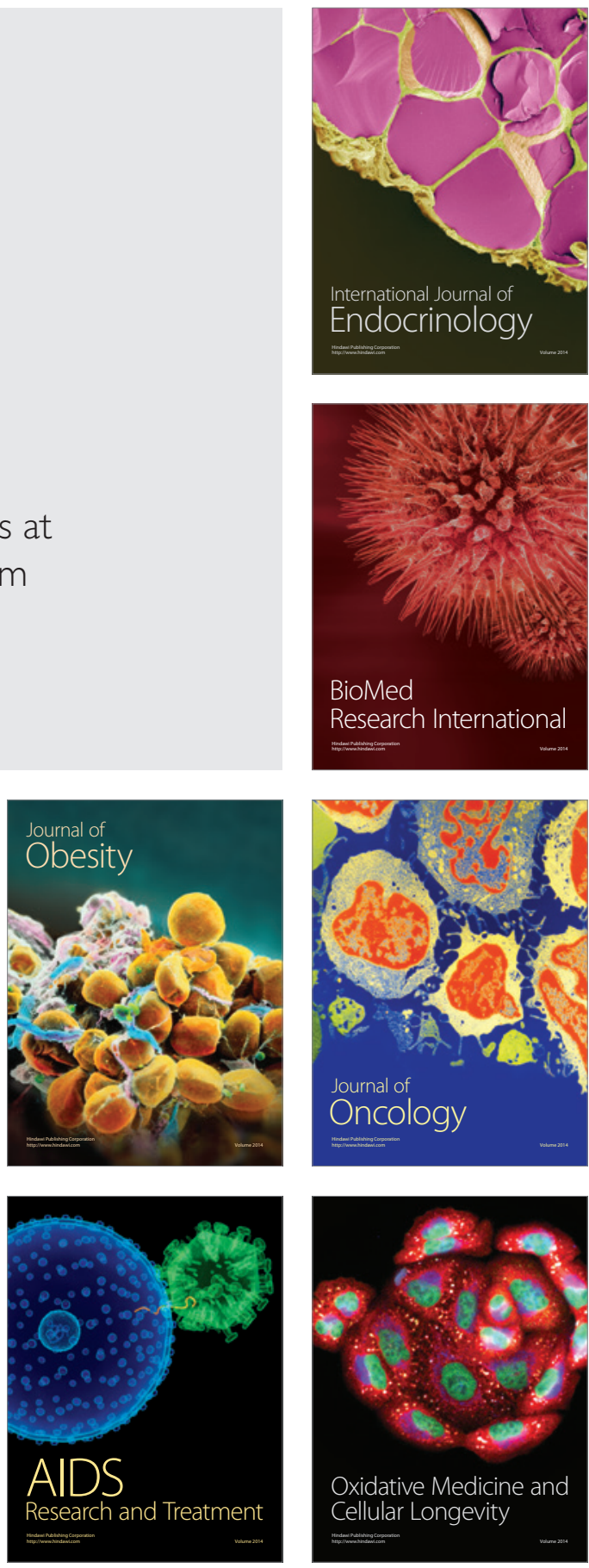